\title{
الرسوم الميوانية المنفذة على المنسوجات الأندلسية الإسلامية
}

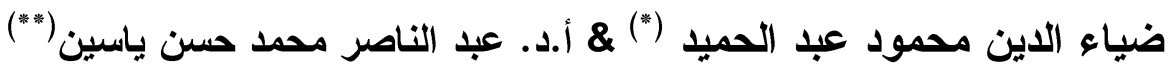

\section{ملفص البهث}

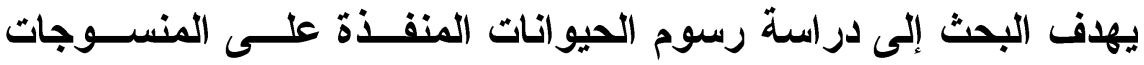

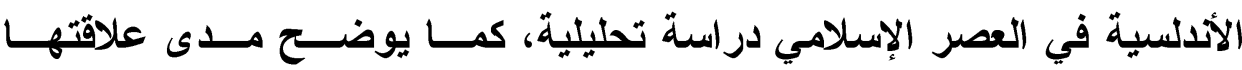
بمثيلاتها المنفذة على الفنون الأدلدية المعاصرة لها، بالإضافة إلى ذلك فيلك فيهذف

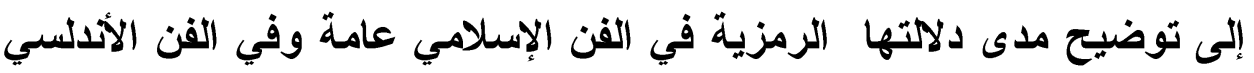

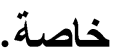
مقدمة ماصة

تعتبر المنسوجات من الاحتياجات الضرورية في الحياة التي لا غنى الته

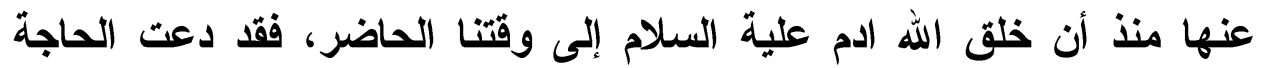

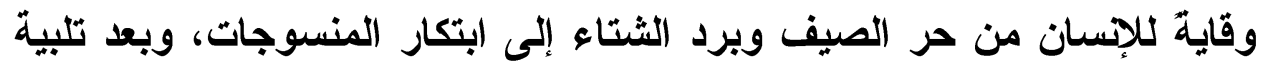

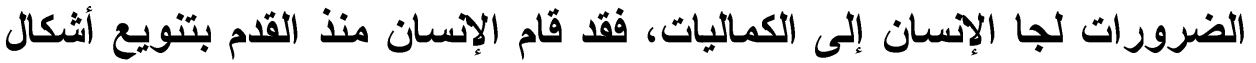

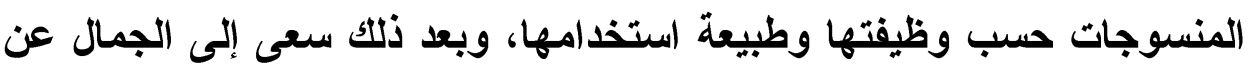

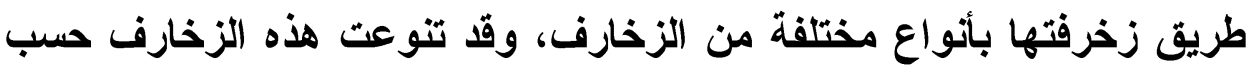

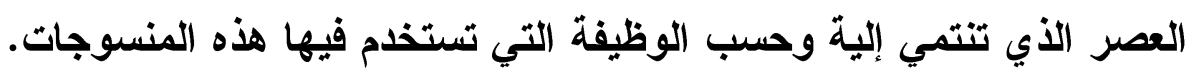

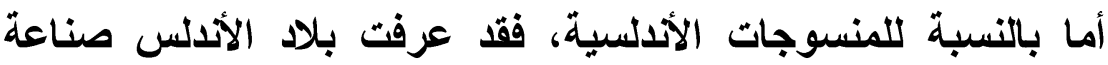

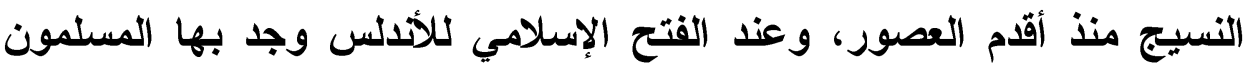

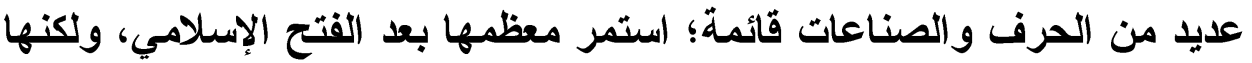

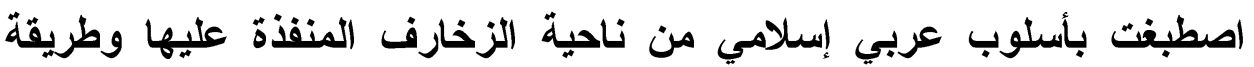
تنفيذها.

(") باحث ماجستير - قسم الآثار الإسلامية ـ كلية الآثار - جامعة سو هاج.

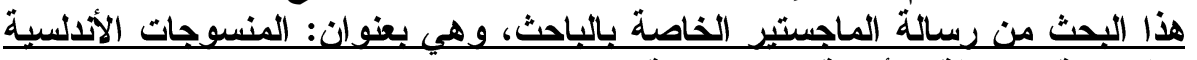

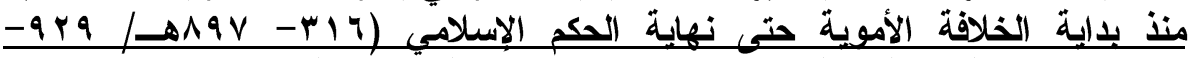

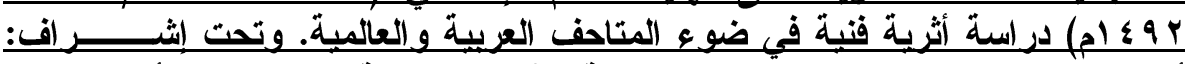

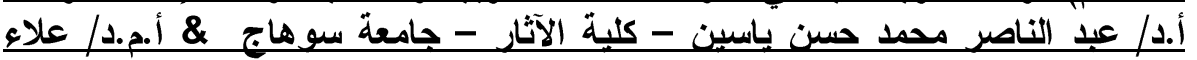

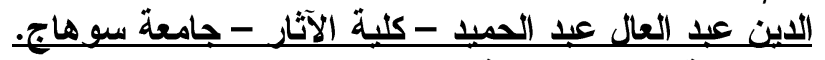

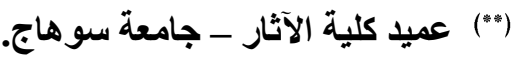


لقد ازدهرث صناعة المنسوجات طوال العصر الإسلامي في الأدلس الأل خاصة في القترة من العصر الأموي وحتى نهاية الحكم الإسلامي.

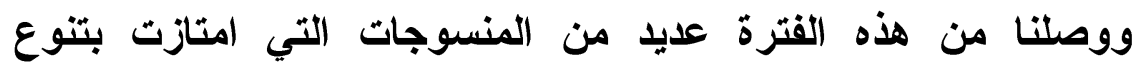
زخارفها ما بين زخارف أدمية وحيوانية وطيور وكائنات خرافية وزخارف منات فئن نباتية وهندسية وكتابية وغيرها.

ومن ناحية أخرى فقد تعددت المواد الخام المستخدمة في صنابهاعة وناعة النسيج خلال هذه الفترة، كما تنوعت طرق صناعتها وأساليب زخرفتها وتعددت ألو انها أيضاً.

\section{الر سلسوم الهيوانـية}

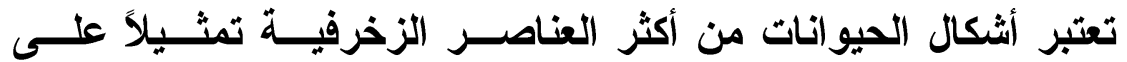

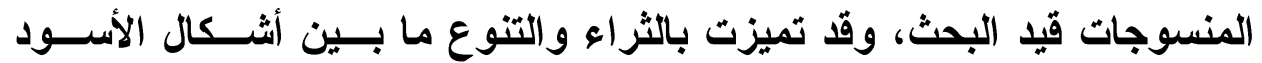

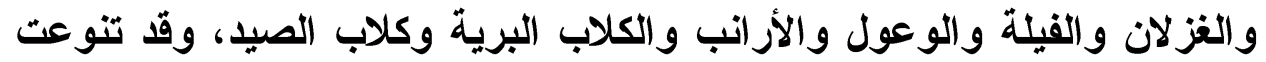

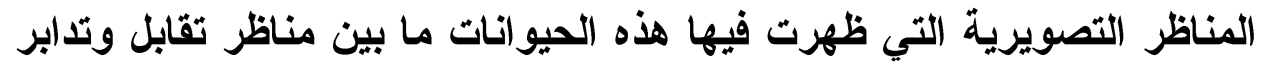

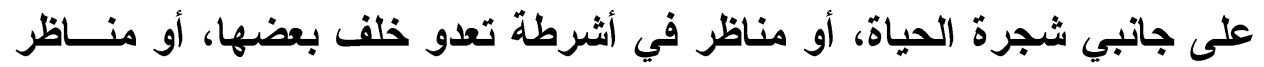

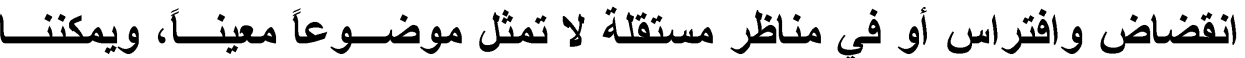
دراسة هذه الحيوانات على النحو التالمي: الأسند

يجمع على أسود وأسد وآسد وآساد ، ويقال لله أيضاً الليث والضيغم

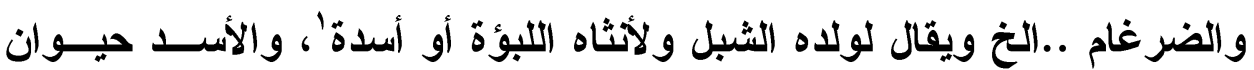
مفترس كبير الحجم وهو من الفصيلة السنورية في رتبة الضواري التي تتميز

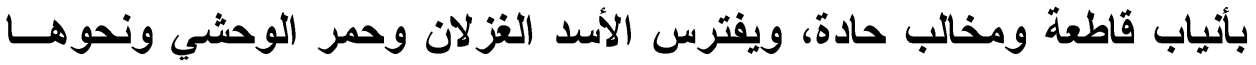

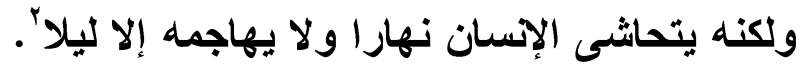

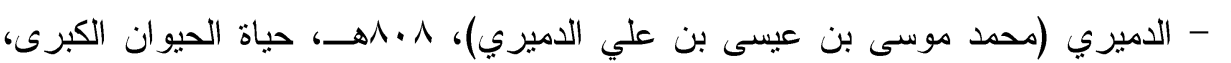

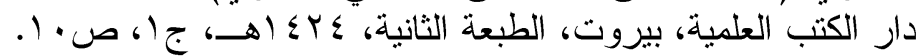

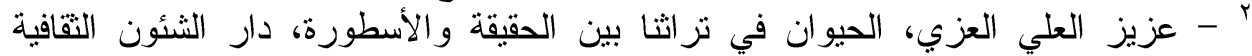

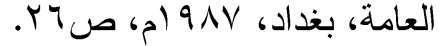


والأسد من الحيوانات التي استُخدمت في كثير من الحضارات القديمسـة

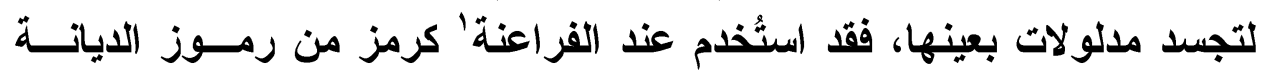

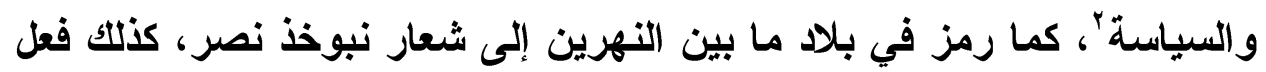

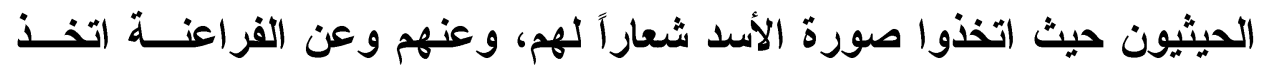

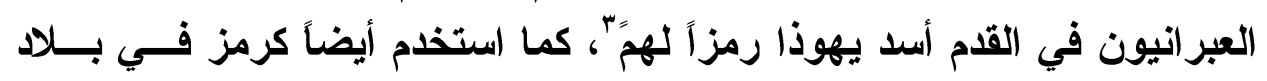

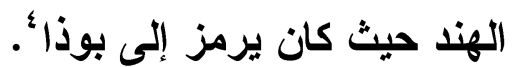

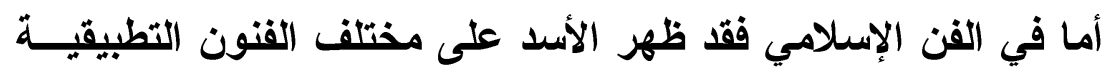

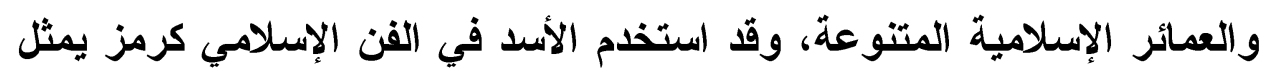

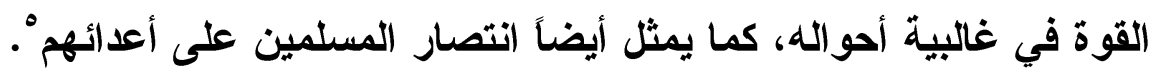

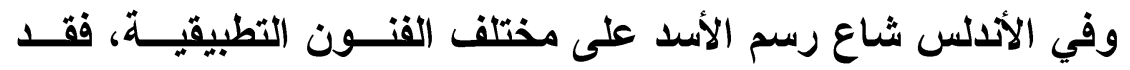

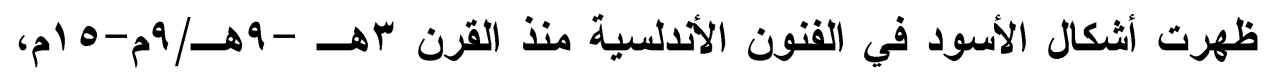

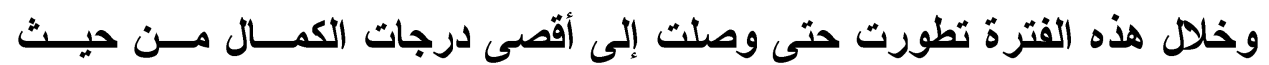

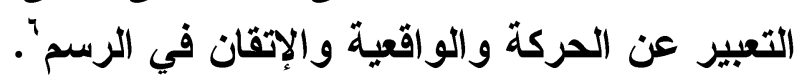

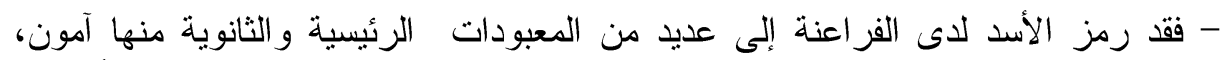

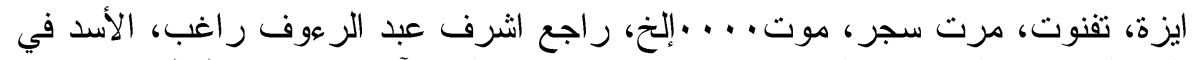
الفن المصري القديم، رسالة ماجستير غير منشورة، كلية الآداب، جامعة طنطا،

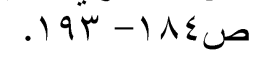

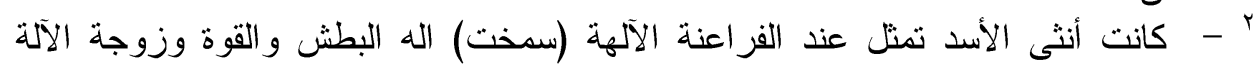

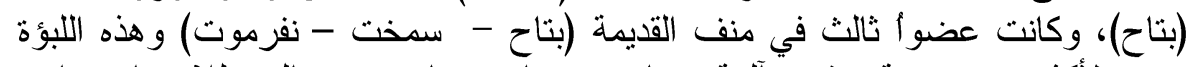

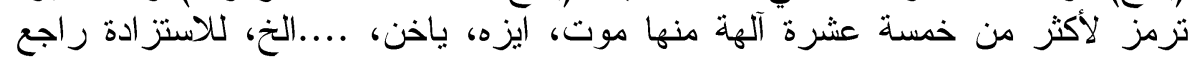

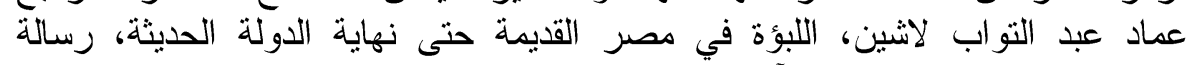

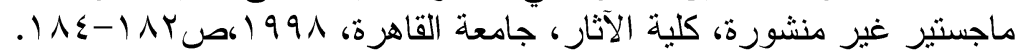

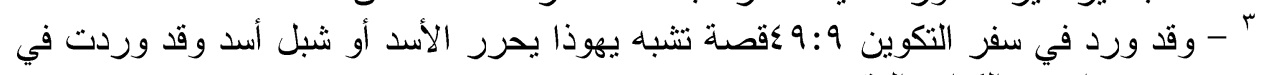
عدة مو اضع بالكتاب المقدس. ؛ - - عبد الناصر ياسين، الرمزية الدينية، مكتبة زهراء الثرق، القاهرة، الطبعة الأولي،

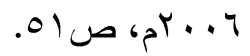

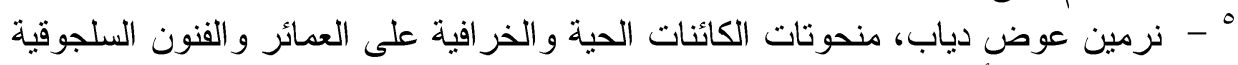

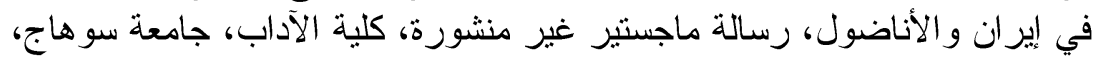

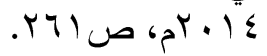
' - حنان عبد الفتاح مطاوع، التحف و الصناعات المعدنية في الأندلس منذ قيام الدولة الأموية

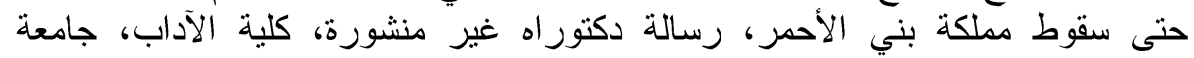

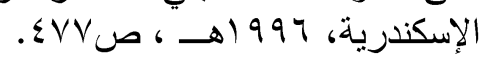




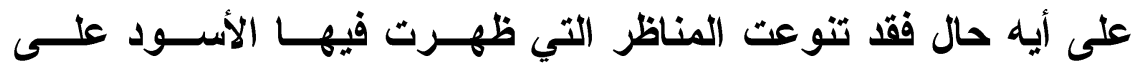

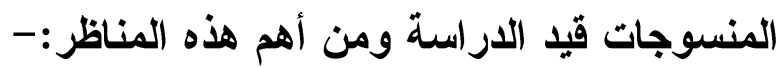

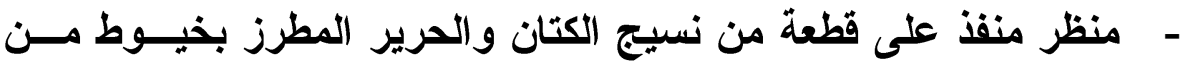

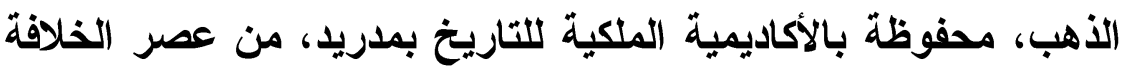

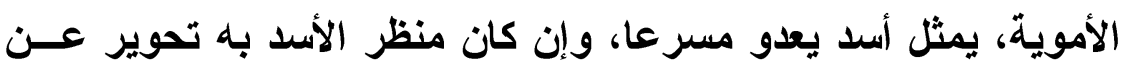

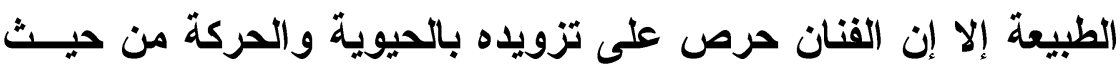

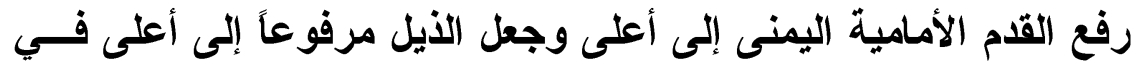

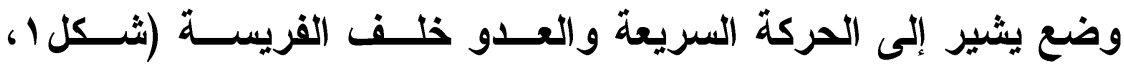
لوحة ام). - منظر منفذ على قطعة من نسيج الحريز المطرز بخيوط مــن الـــذهب،

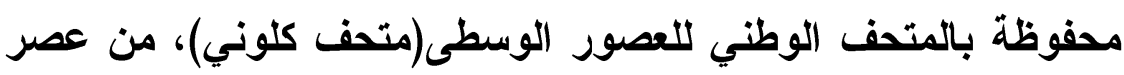

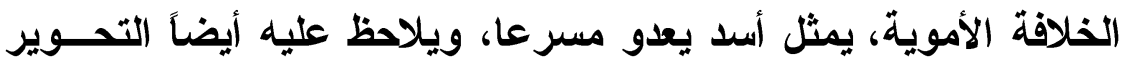

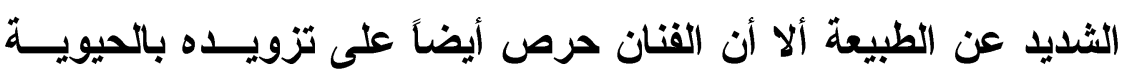

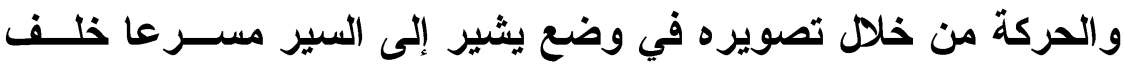

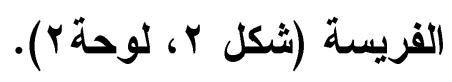

- منظر منفذ على قطعة من نسيج الحريز المطرز بخيوط مــن الــــهب،

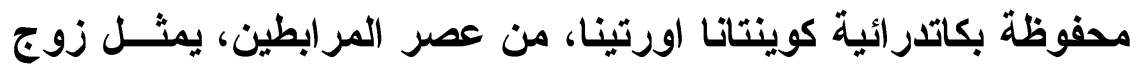

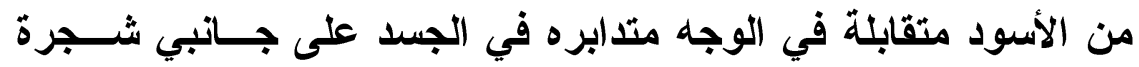

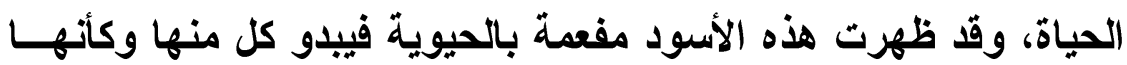

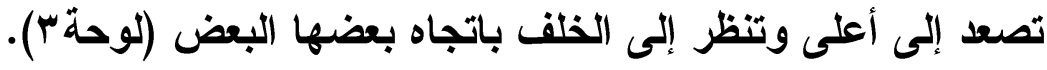

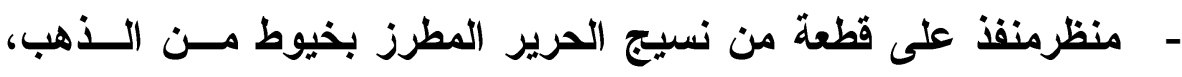

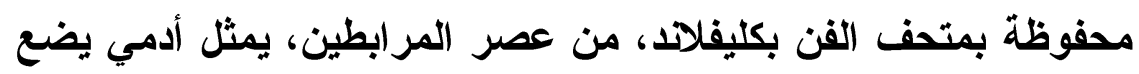

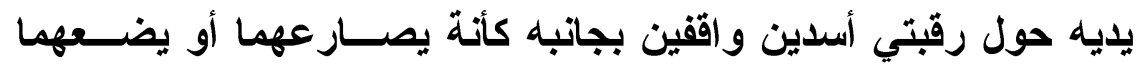

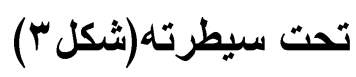

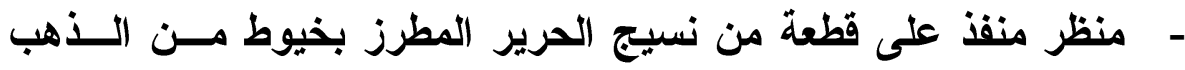

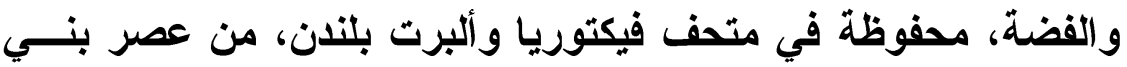

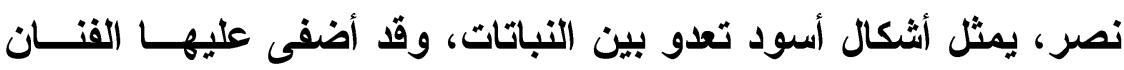




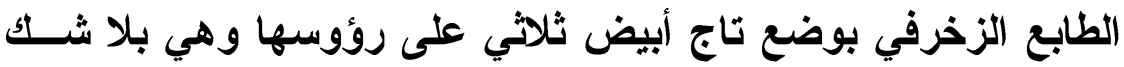

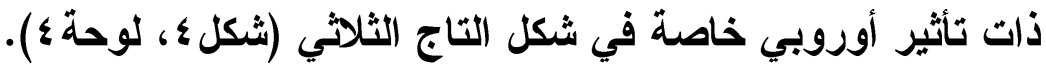

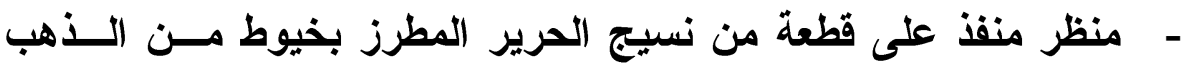

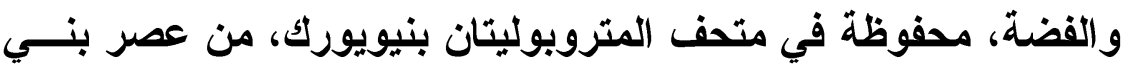

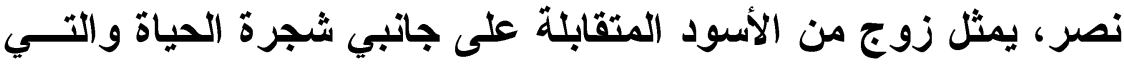

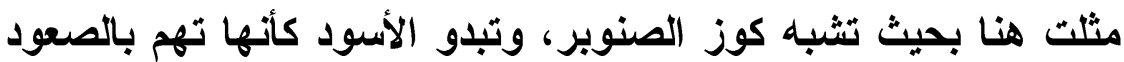

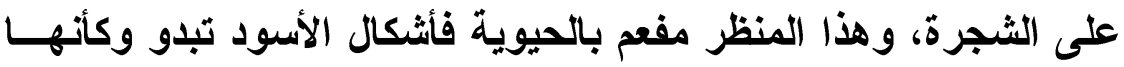

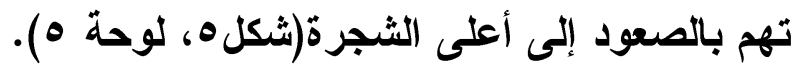

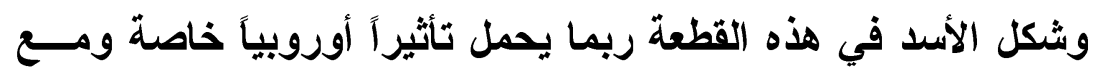

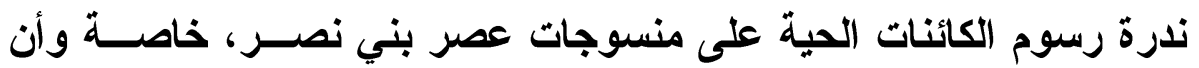

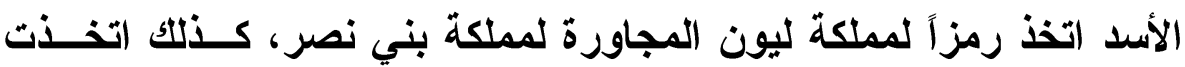

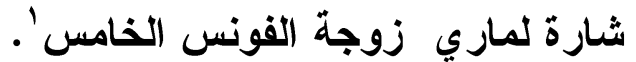
وقد تميزت مناظر الأسود المنفذة على المنسوجات قيد الاراســـة

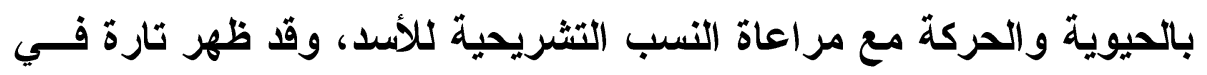
وضع جاتبي ورأسه في وضع مواجهة تامة، ومثل تارة أخرى في وضــــع جانبي في الجسم والر أس. ولم يقتصر ظهور أشكال الأسود على المنسوجات الألدلسية فحسب، فقد ظهرت أيضاً على التحف المعدنية حيث وصلتنا عدة تحف معدنية مزينة

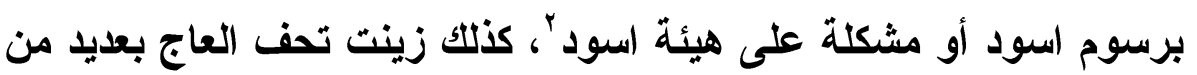

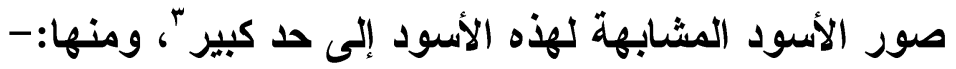

' - محمد عبد العزيز مرزوق، الفنون الزخرفية الإسلامية في المغرب و الأندلس، بيروت،

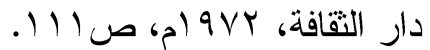

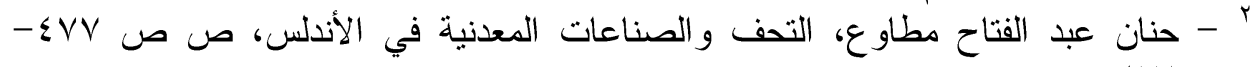
r - السيد عبد العزيز سالم، تحف العاج الأندلسية ، مؤسسة شباب الجامعة، الإسكندرية، 990 ام ص ص. 990 
- تمثال من البرونز محفوظ بمتحف اللوفر بباريس يمثل أسد فــاغراً

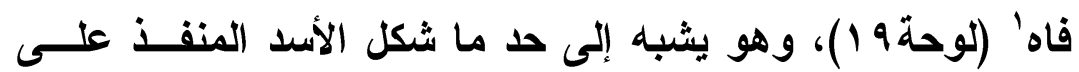
قطعة النسيج(شكل r ب، لوحة باه ).

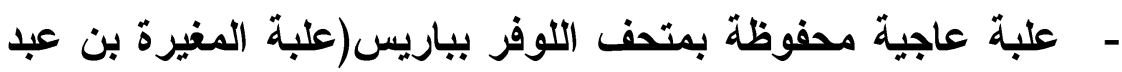

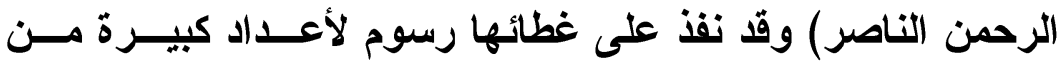

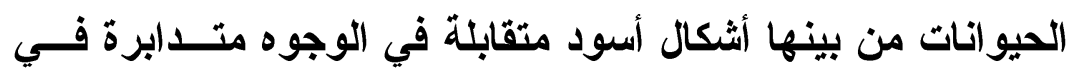

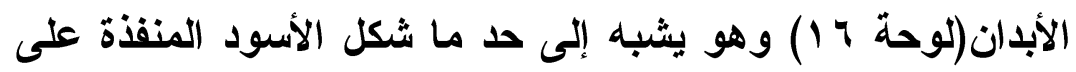
قطعة النسيج (لوحةب).

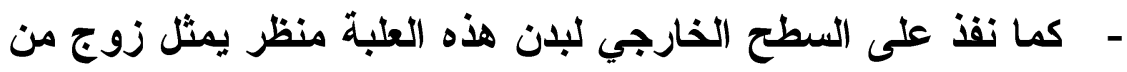

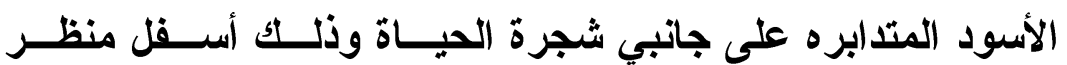

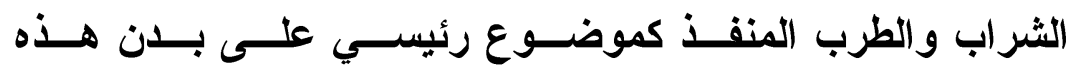

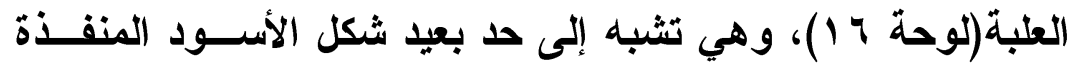

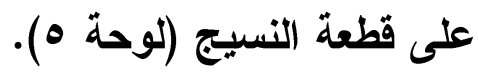

الفهل: جمعة فيال وفيول وفيلة، ويقال إن الفيل الأكر والاندبيل الأثثى، وهو

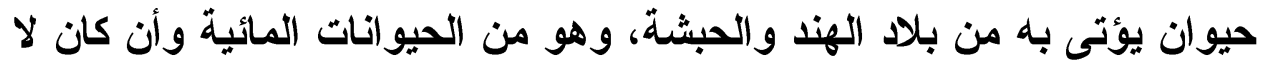

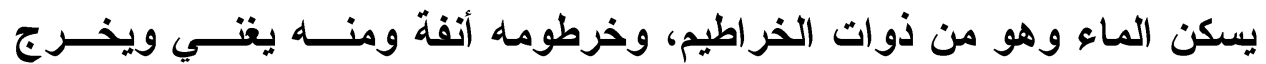

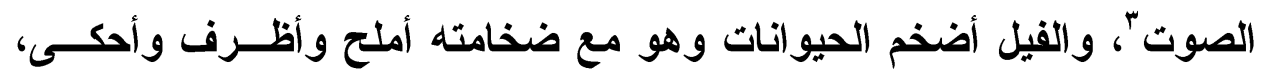
وهو يفوق في ذلك كل خفيف الجسم رشيق الطبيعة؛، ويعد الفيل حيواناً شديداً كان يسخر في حمل الأثقال أو جرها، وقد استخدمت الفيلة كثيراً فــي العمـلـل

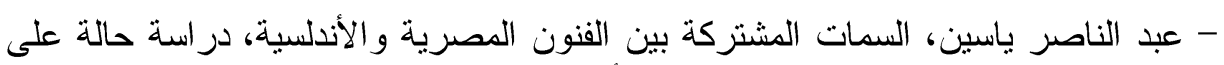

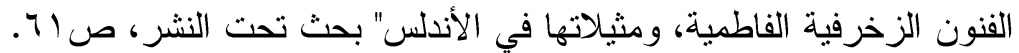

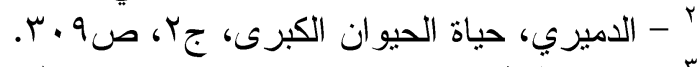

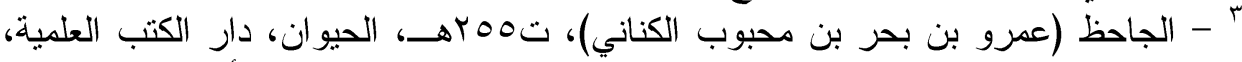

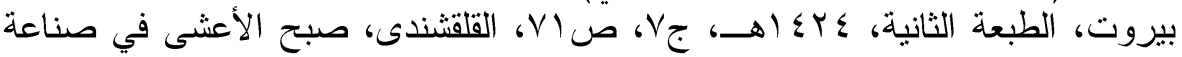

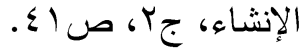

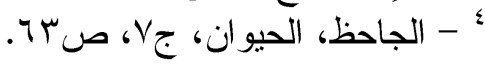


و الصيد وكذلك في الحروب وكان كبار القوم يفخرون ويتباهون بما يملكون من

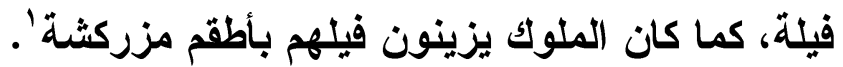

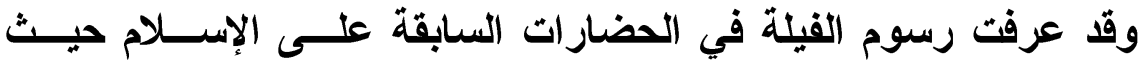

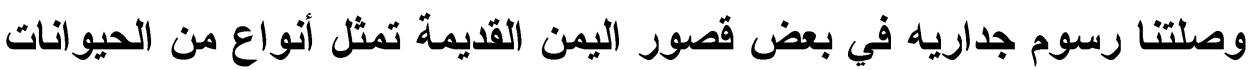

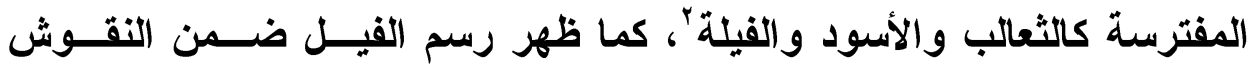

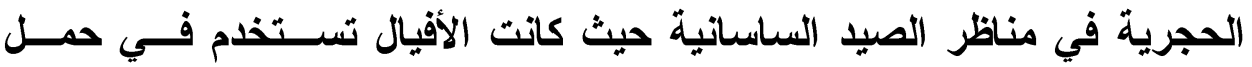
العرش الملكي أثناء التوجه إلى ساحة الصيدّاّ.

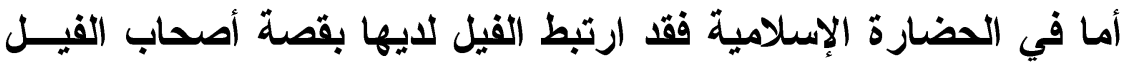

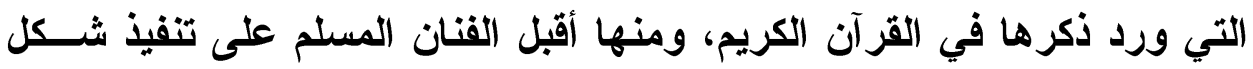

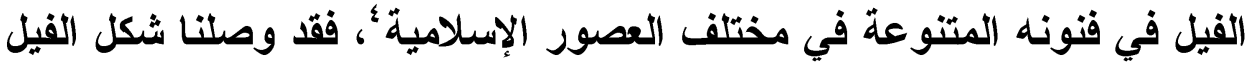
منذ بداية العصر الإسلامي وعلى مر العصور الإسلامية.

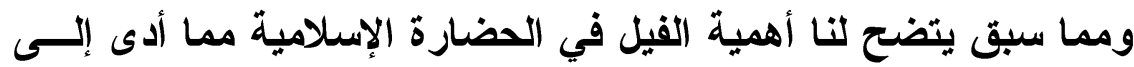
انتثاره في الفن الإسلامي، ومن أهم مناظر الفيلة المنفذة على المنسوجات قيل فيل

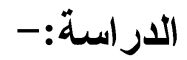

- منظر منفف على قطعة من نسيج الحرير المطرز بخيوط مـن الــــهب،

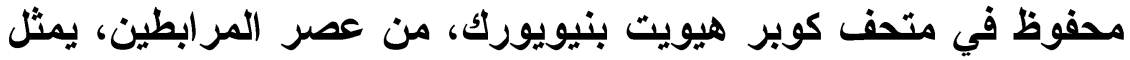

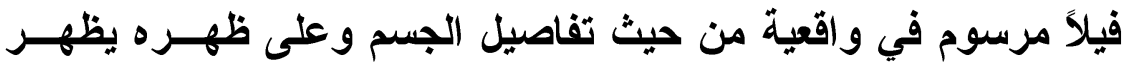

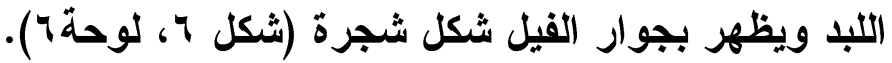

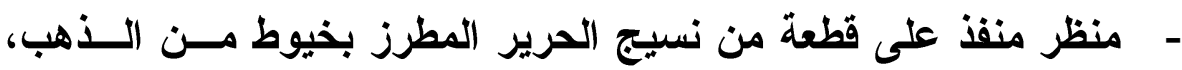

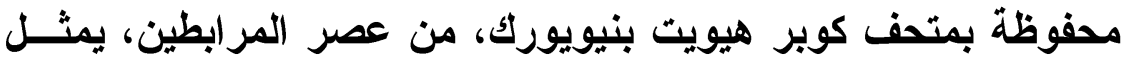

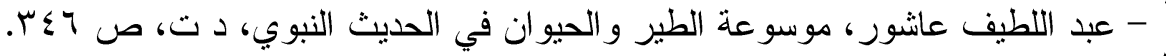

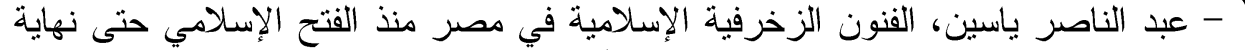

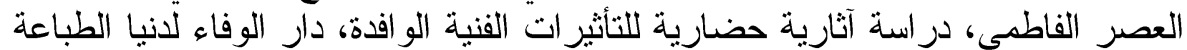

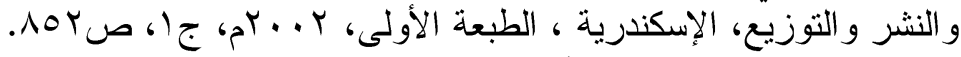

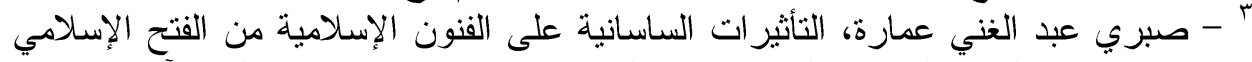
حتى نهاية القرن الخامس الهجري، رسالة ماجستير غير منشورة، كلية الآثار ، جامعة الألئ

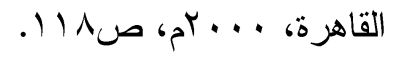

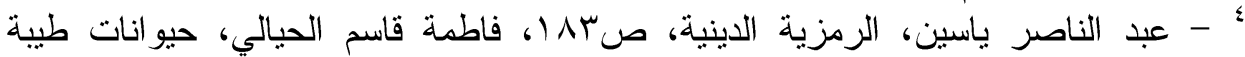

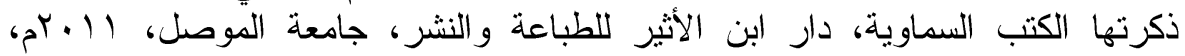


فيلاً يغطي ظهره سرج، وقد بالغ القنان في حجم أذن الفيل، ويعلو ظهر

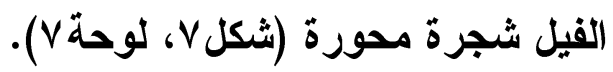

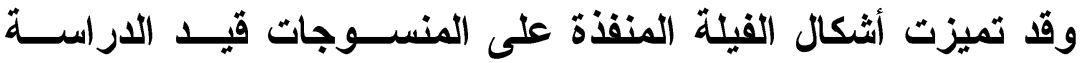

بالحيوية والحركة أحياناً فقد أضفى عليها الفنان طابع الحركة من خلال تقـــيم القدم الأمامية اليسرى على اليمنى في وضع يشير إلى العدو والحركة، في حين صورها في البعض الآخر وهي تمتاز بالجمود حيث تبدو ثابتة لا حركة فيه فئس

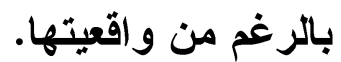

ولم يقتصر رسم الفيل على المنسوجات الألدلسية حيث وصلتنا أثكال

فيلة منفذة على تحف العاج الأندلسية وهي تشبه إلى حد كبير أثــكال الفيلــة

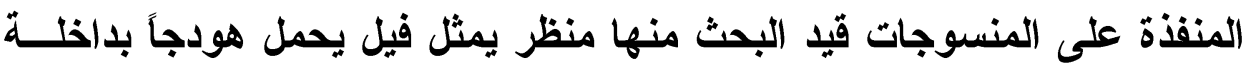

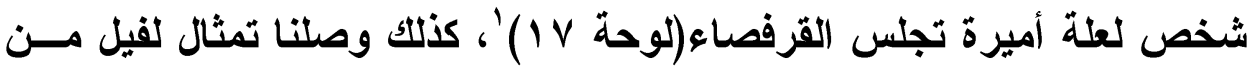

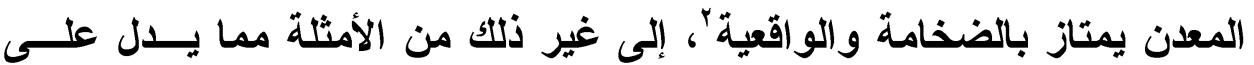
انتشار رسم الفيل في القنون الأدلأسية.

\section{الغزلان والظباء}

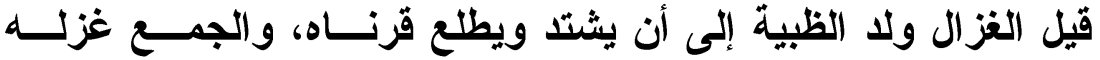

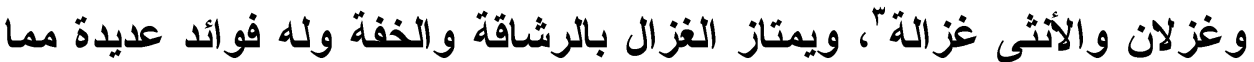

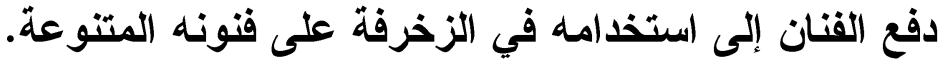

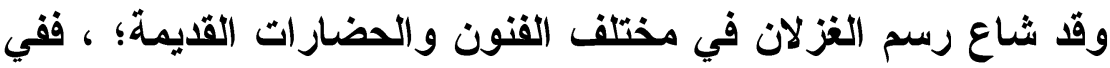
الفن الفرعوني اعثُر أن الغزال من أعداء الثمس فصور المصري القديم الأسد

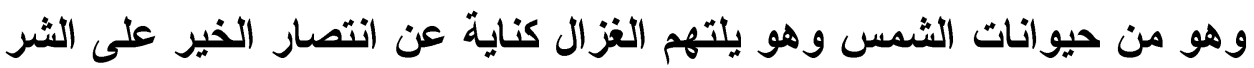

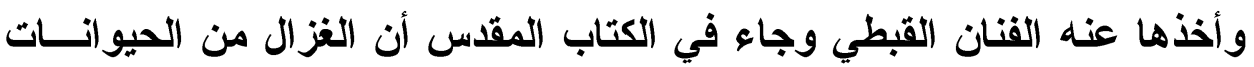

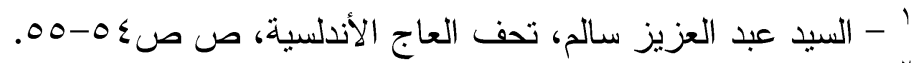

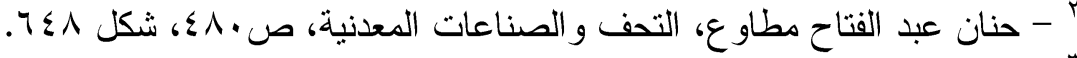

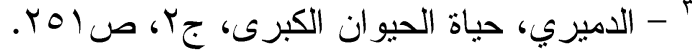




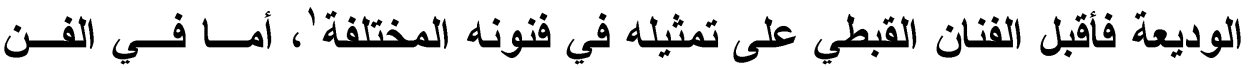

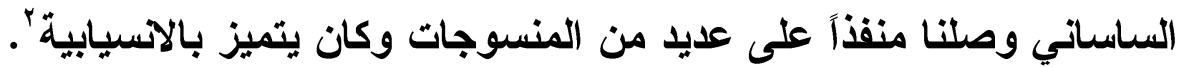

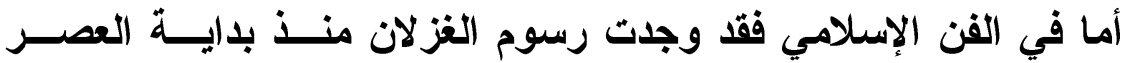

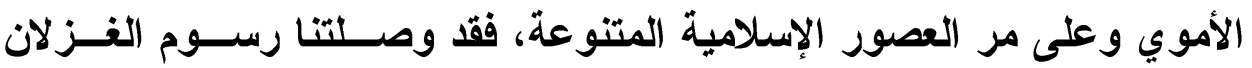

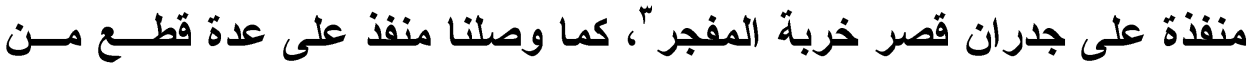

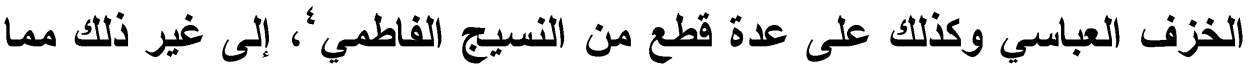

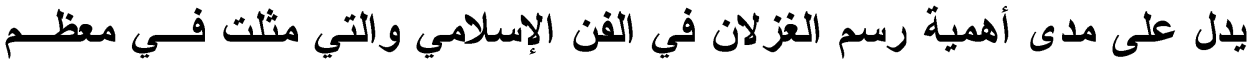

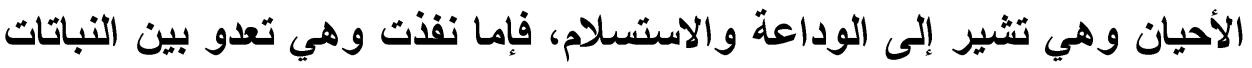

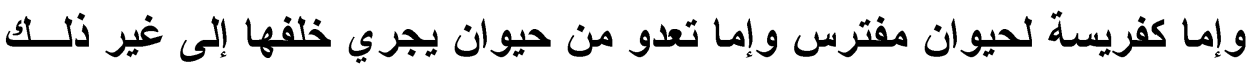
من المناظر التي تلد على وداعة هذان الحئ الحيوان.

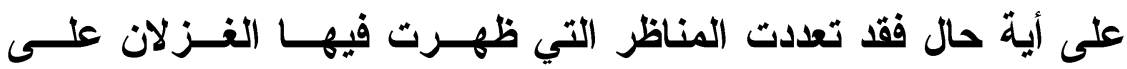
المنسوجات قيد الدراسة ومن أهم هذه المناظر :-

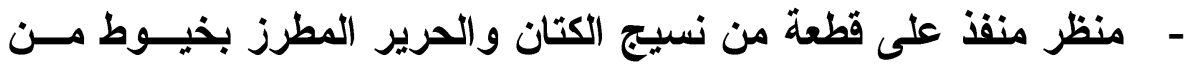

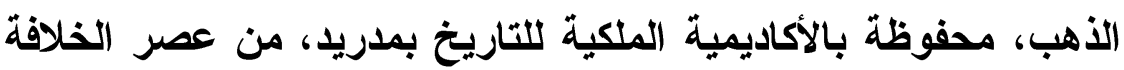

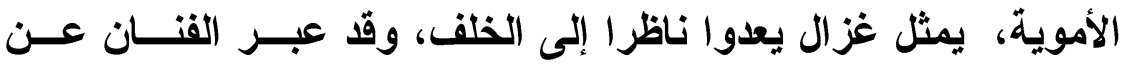

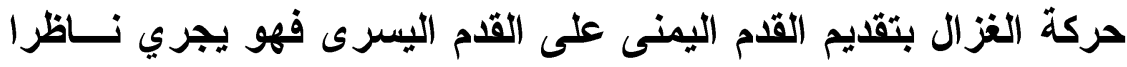

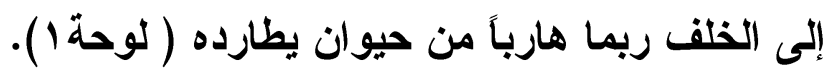

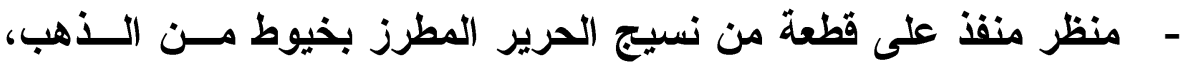

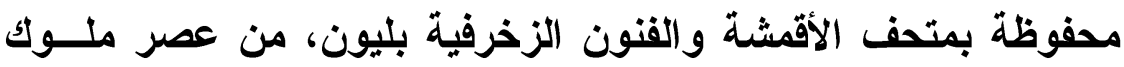

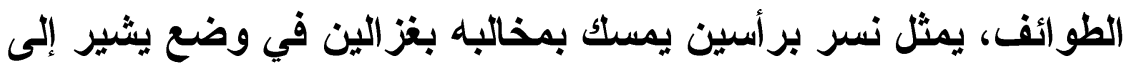

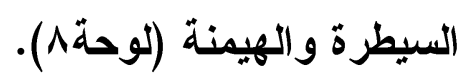

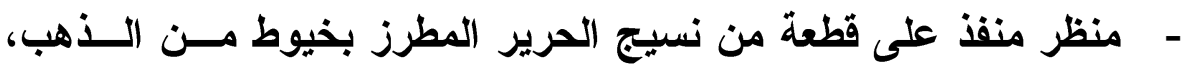

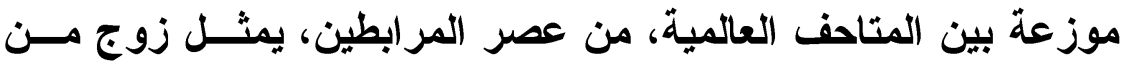
- جمال هرمينا بطرس، الأشكال غير النقليدية في الفن القبطي، ندوة الآثار القبطية،

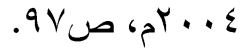
r - ثريا محمود عبد الرسول، العناصر الحيوانية توثيق وتوصيف على النسيج الإسلامي،

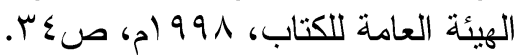

3 - Robert Irwin, Islamic art Laurence King, 1997 -P43, fig 56.

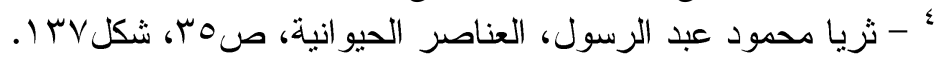


الغزلان الصغيرة تعدو بين أقدام الطواويس المنفذة بحجم كبير (شـكل

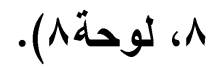
- منظر منفذ على قطعة من نسيج الحرير المطرز بخيوط مسـن الــذهب، موزعة بين المتاحف العالمية، من عصر المر ابطين، يمثل أزواج مــن فئن

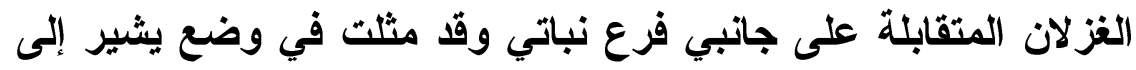

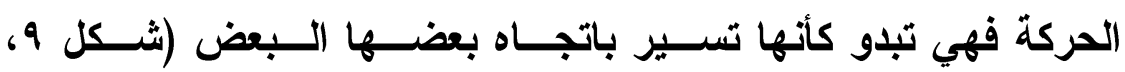

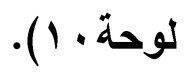

- منظر أخر على نفس المنسوجة الســابقة، يمثـل زوج مــن الغــزلان

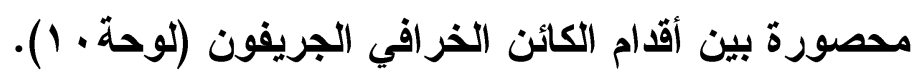

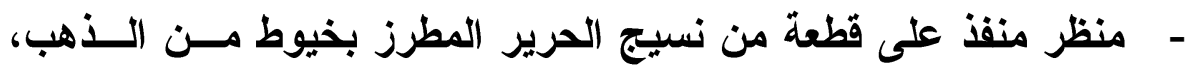

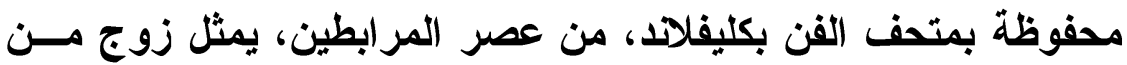

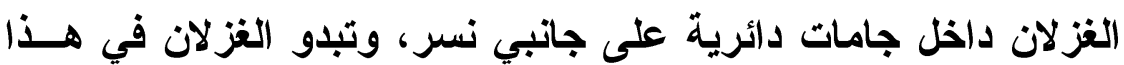

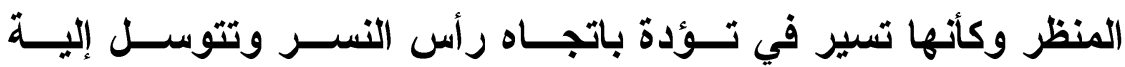

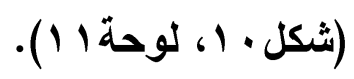

ومن العرض السابق لمناظر الغزلان على المنسوجات قيد الدراسة نجد

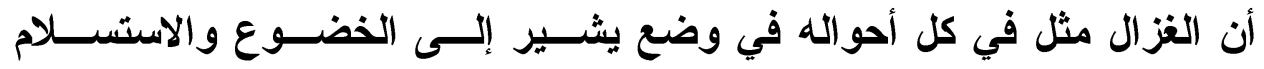

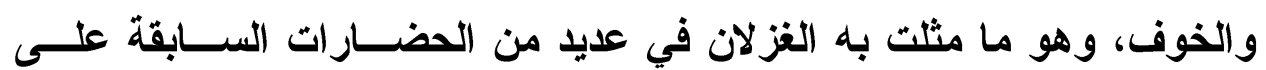
الإسلام وكذلك في الحضارة الإسلامية أيضاً.

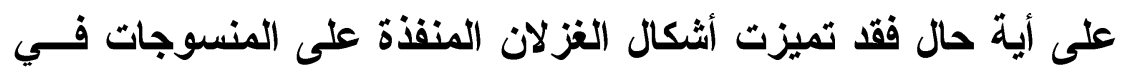

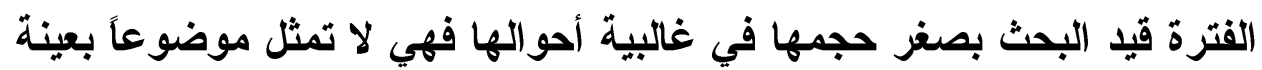

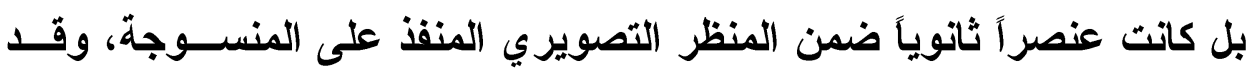

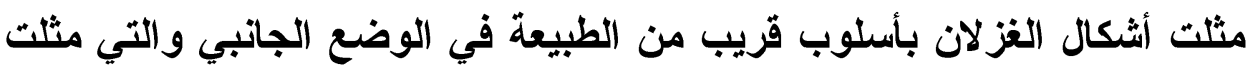

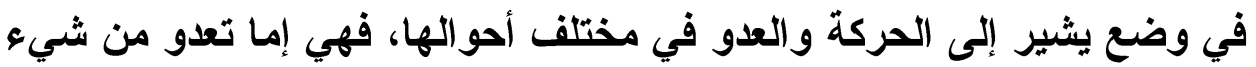
يطاردها أو تعدو لتصل إلى هدف إلى معين.

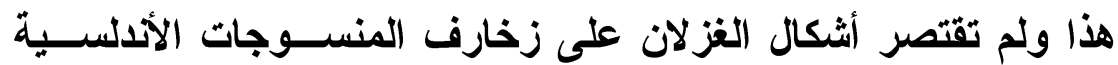

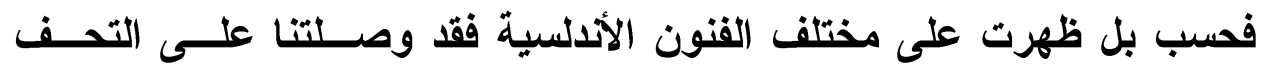




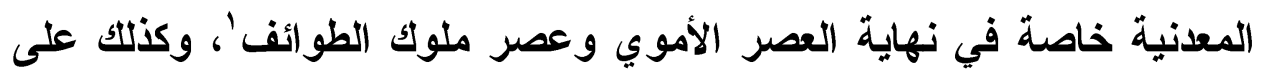

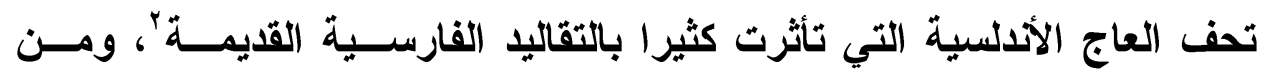
أهمها:- ألعاج

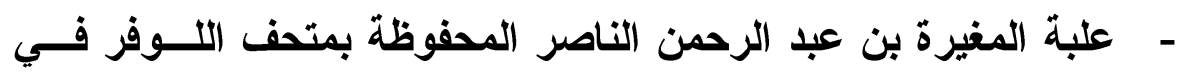

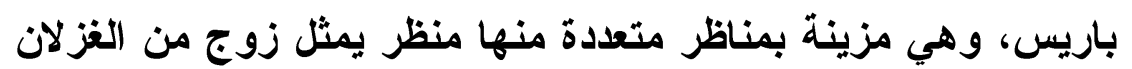

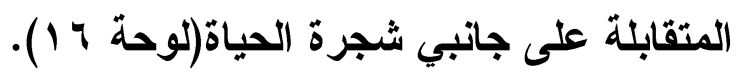

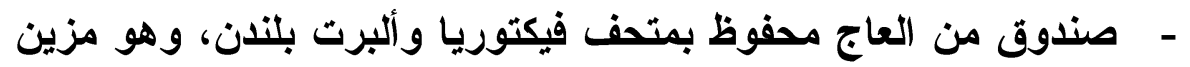

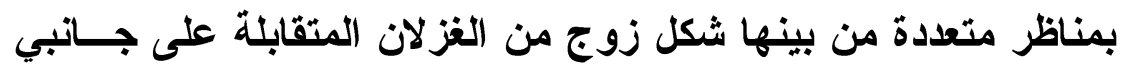
شجرة الحياة (لوحةم 1 ).

1الكلاب:

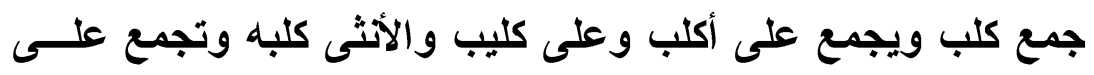

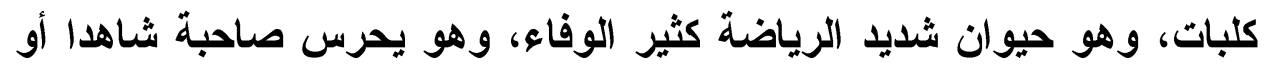

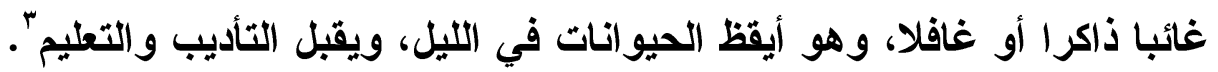

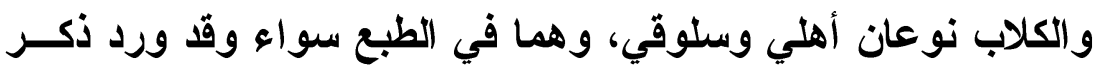

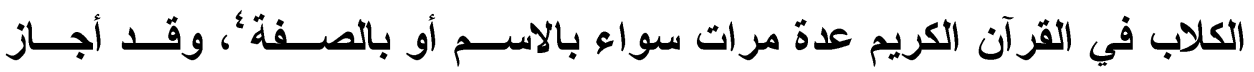

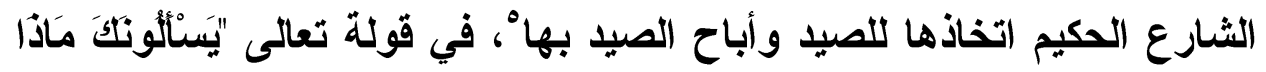

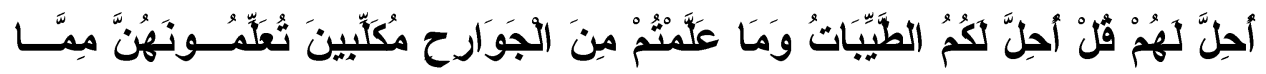

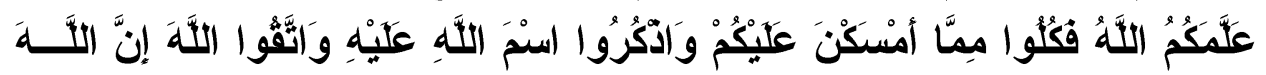

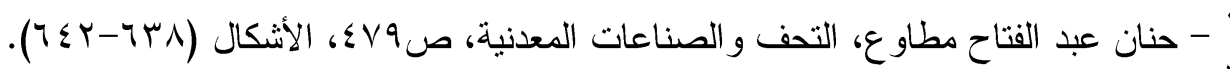

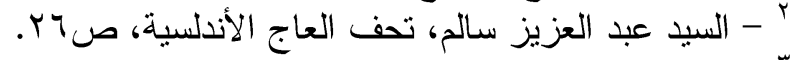

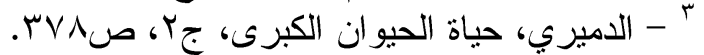

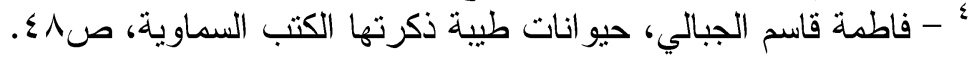

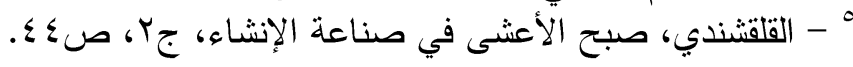


مجلة كلية الآداب، جامعة سوهاج، العدد الخامس والأربعون، الجزء الأول، أكتوبر IV P P

سَريعُ الحسًَِاب "'، أي أن هذه الكلاب واستخدامهاب في الصيد اقر به الإســلام

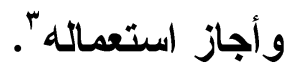

ومما هو ثابت في السنة النبوية عدم دخول الملايكة في الأماكن التي

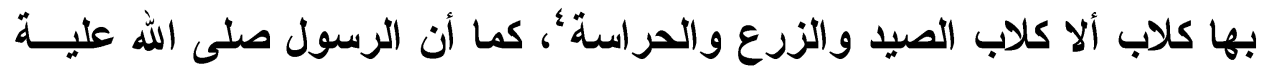

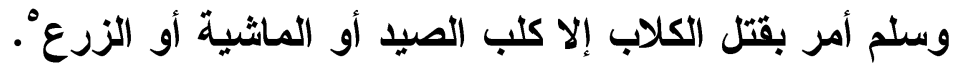

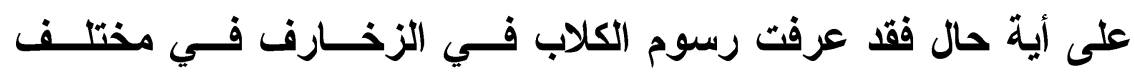

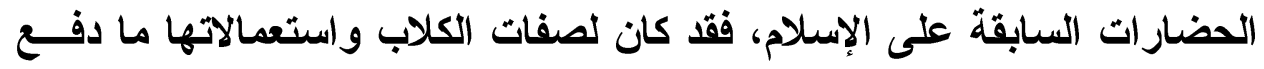
الفنان على تنفيذها في فنونه المختلفة خاصة في الفن القبطي الأي أكثر مـنـ

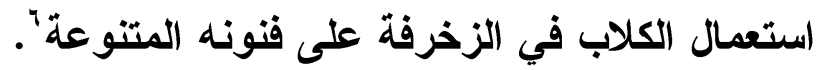

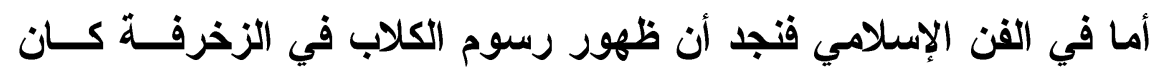
قاصر ا على كلاب الصيد، وفي أحيان قليلة كاتت تظهر مناظر لكلاب تعدو لعلها

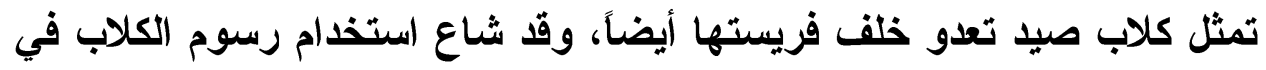
الزخرفة في الفن الإسلامي خاصة في العصر الفاطمي الأي ظهرث فئه فيه منــاظر

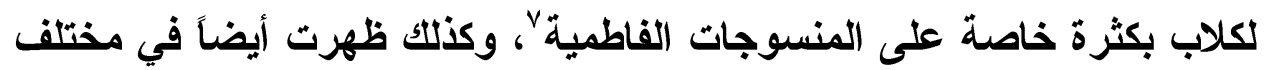

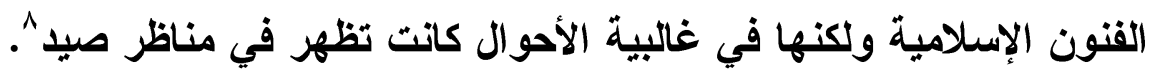

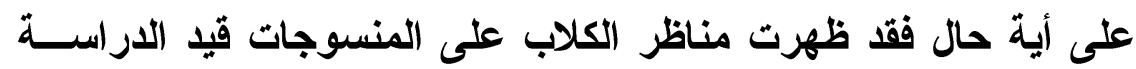

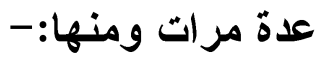

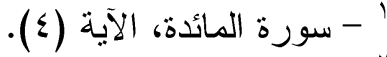

r - للاستز ادة عن استخدام الكلاب في الصيد راجع، عبد الناصر ياسين، مناظر الفروسية،

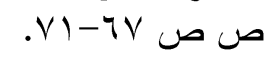

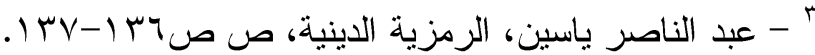

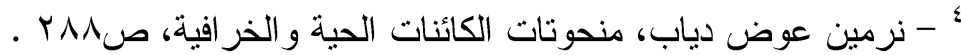

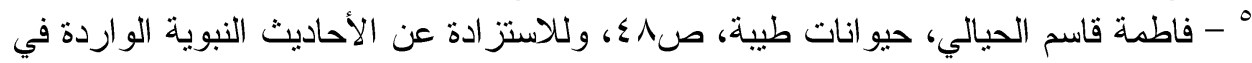

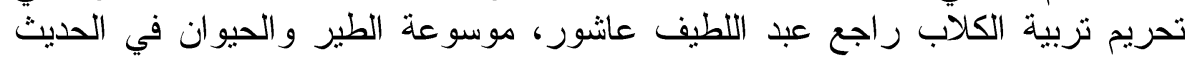

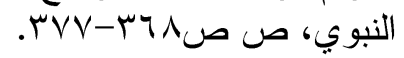

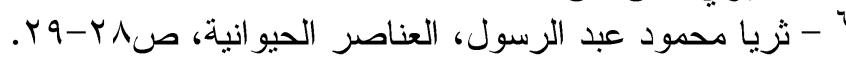

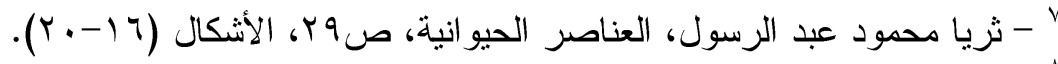

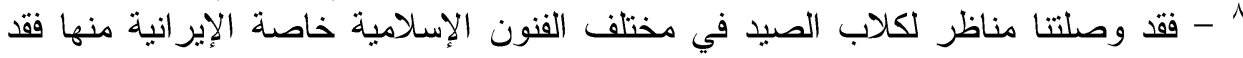

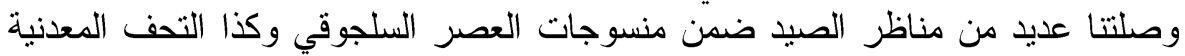

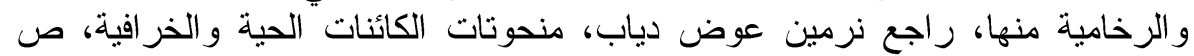


- منظر منفذ على قطعة من نسيج الحرير المطرز بخيوط مسن الـــهب،

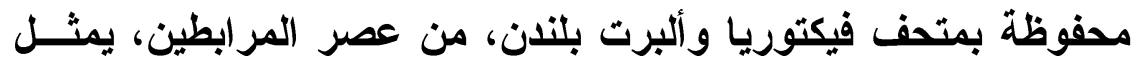

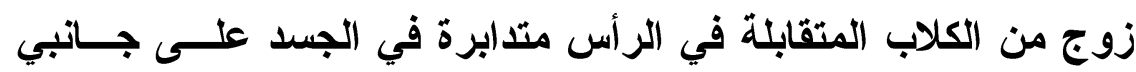

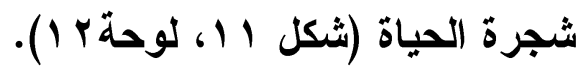

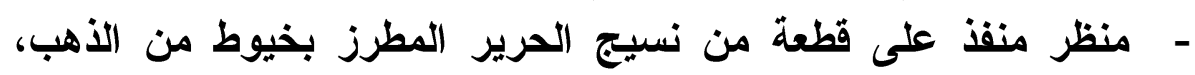

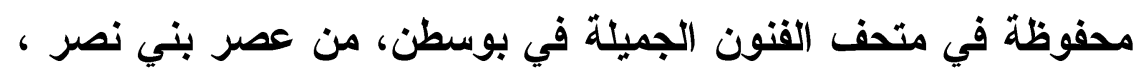

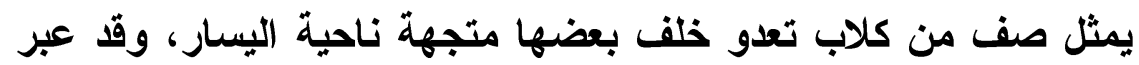

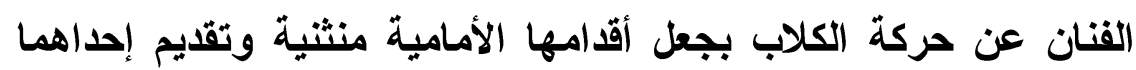

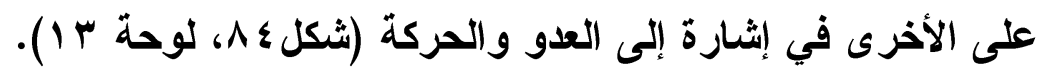

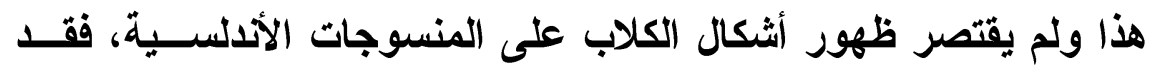

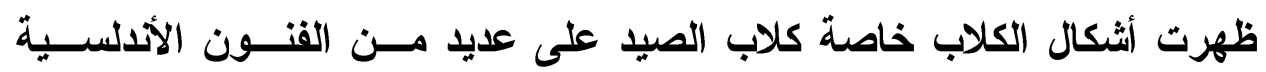

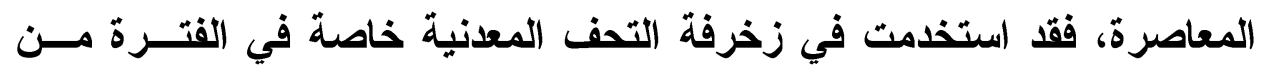

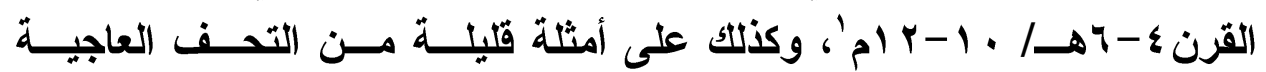

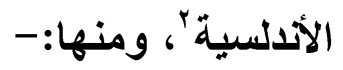

- علبة من العاج محفوظة بمتحف فيكتوريا والبرت بلندن، وهي مزينة

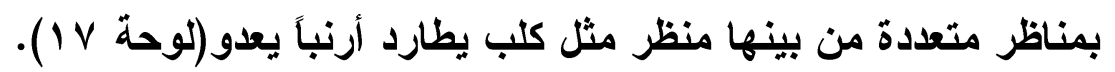

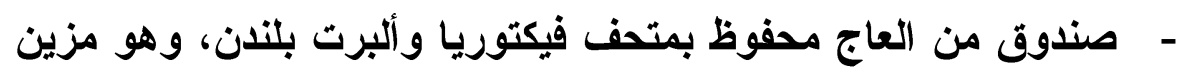

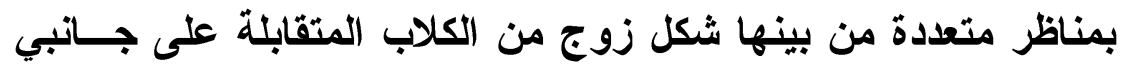

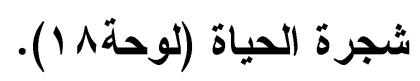

وقد تميزت أثنكال الكلاب المنفذة على هذه التحف بالتعبير عن الحيوية

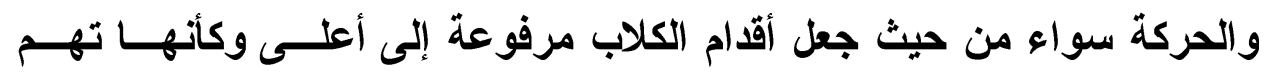

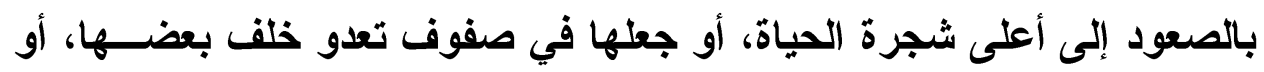
جعها تعدو خلف الفريسة في منظر مطاردة حيو انات أليفة.

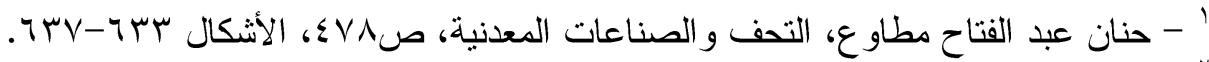

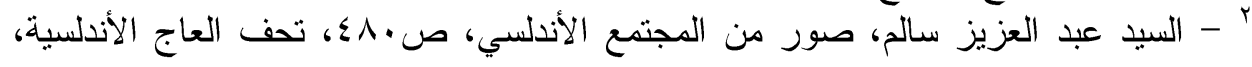
مص 


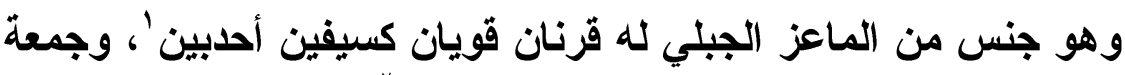

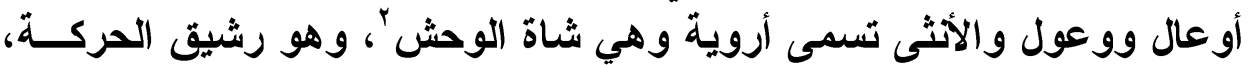

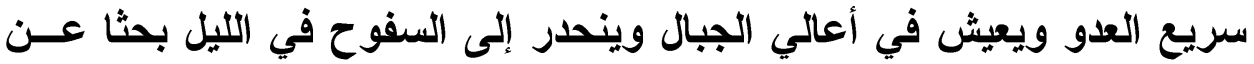

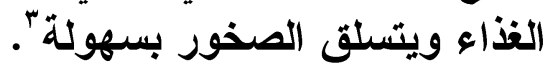
وقد عرف الوعل في الحضارات السابقة على الإسلام خاصة في الفن

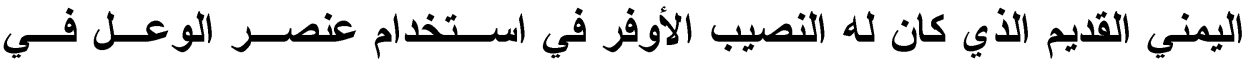

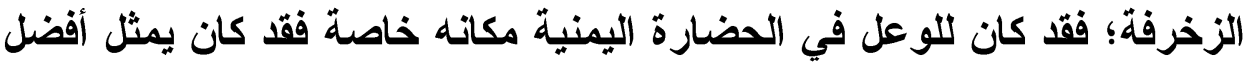

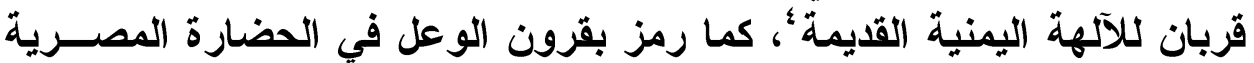

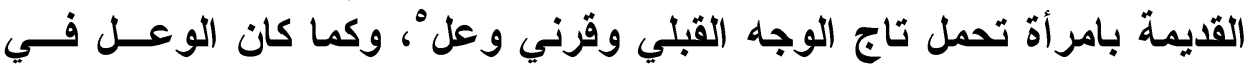

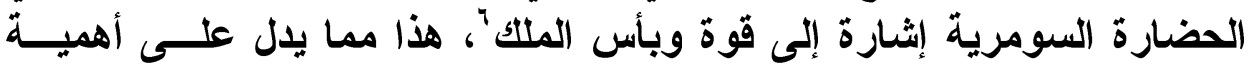
الوعل في الحضار ات السابقة على الإسلام.

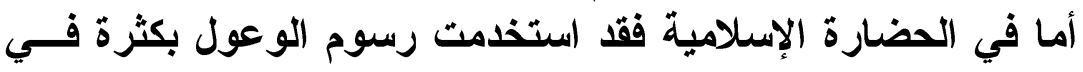

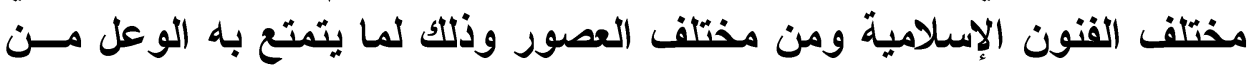
جمال في الثكل وقوة القرون الملتوية كسيفين أحدبين.

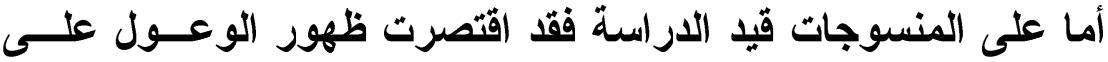
منسوجات القترة المبكرة ق عهــ/ • ام، حيث وصلنا عدة أشكال للوعل وأنثـاه ومنها:-

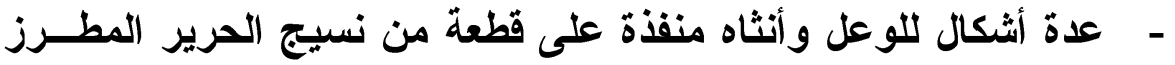

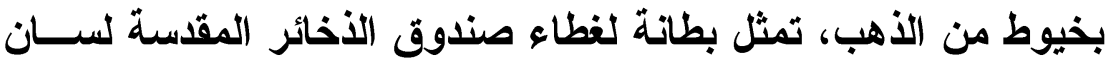

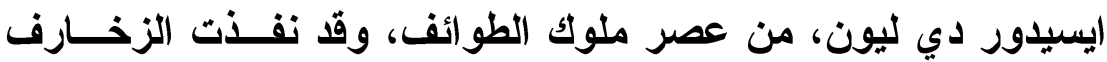

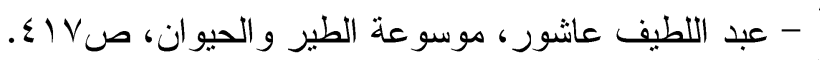

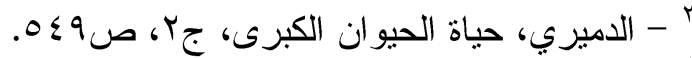

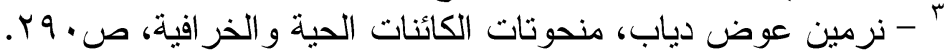

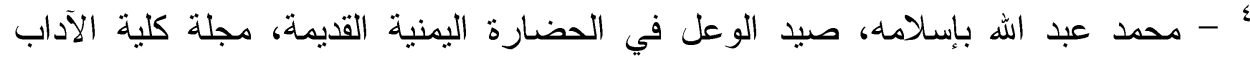
5

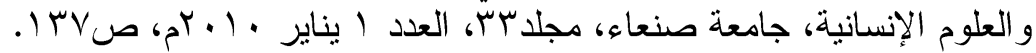

https://ar.wikipedia.org/wiki/\%D8\%B3\%D8\%A7\%D8\%AA\%D8\%A A the last visit 22-7-2016.

" - عماد طارق توفيق، التوظيف الحيو اني في حضارتي بلاد الر افدين ومصر القديمة، مجلة

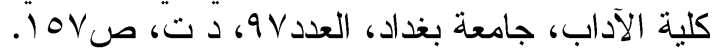




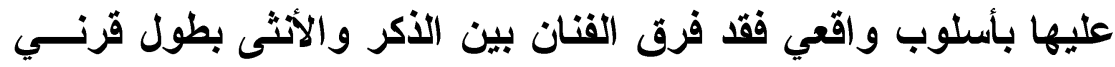

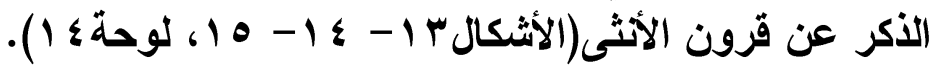

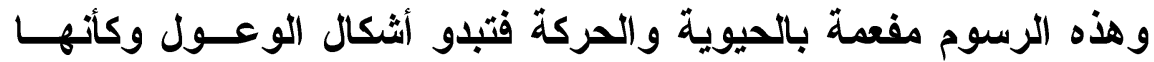

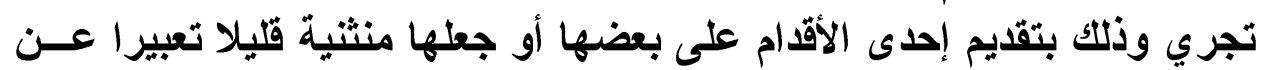

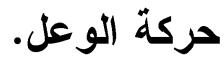

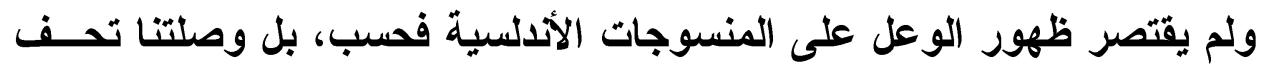
معدنية منفذه على شكل وعل ومل ومنها:-

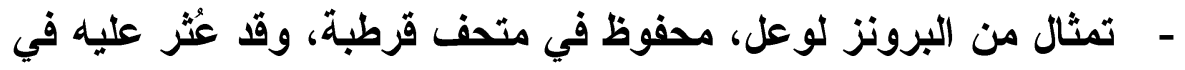

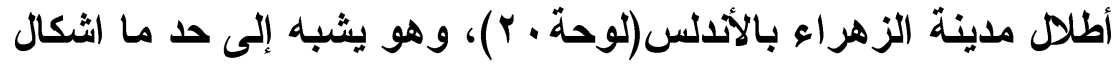
الوعول المنفذة على المنسوجات قيد البحث.

الأرنب يكون للأكر والأثثى والجمع أرانب، وقيل الأرنب الأثثى والخرز 1الأرنب: المبا

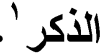

وقد عرف الأرنب في الزخرفة منذ أقدم العصور؛ حيث ظهر في مصر

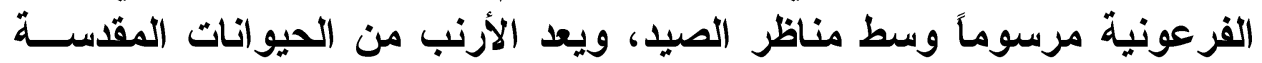

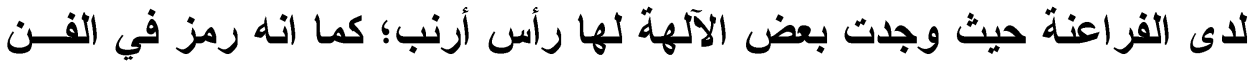

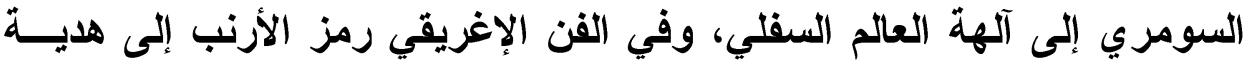

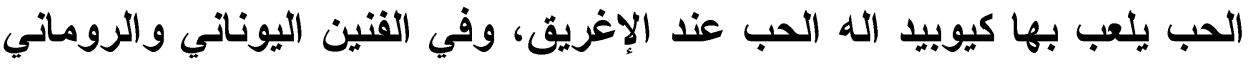

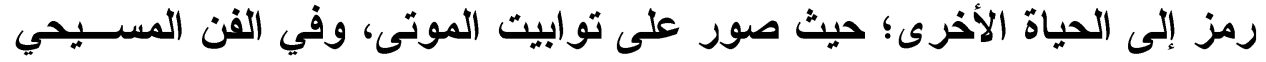

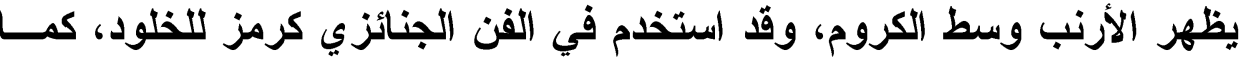

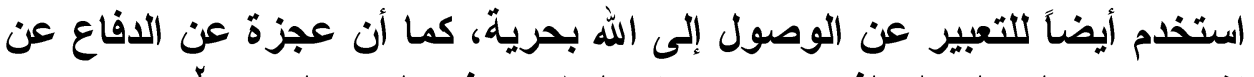

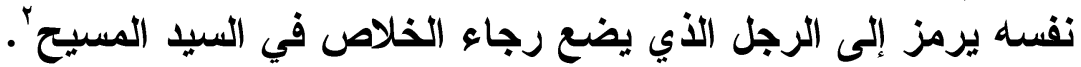

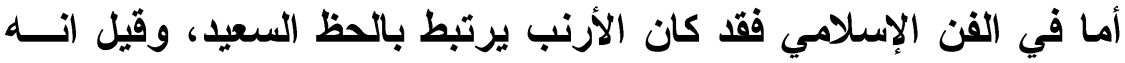

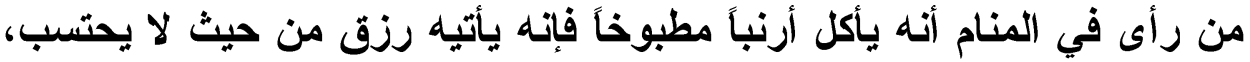

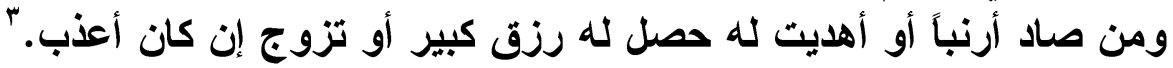

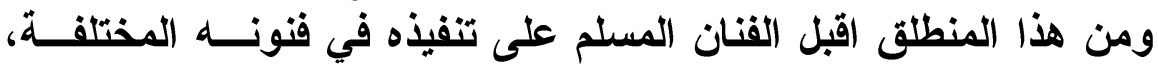

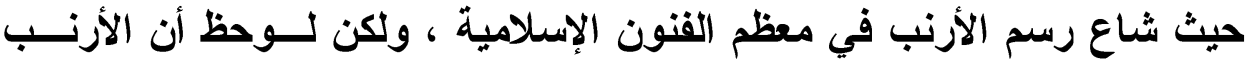
' - هناء محمد عدلي، التماثيل في الفن الإسلامي، دار الجلال للطباعة، القاهرة، ^. .بام،

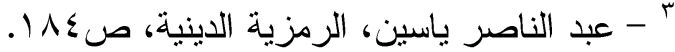




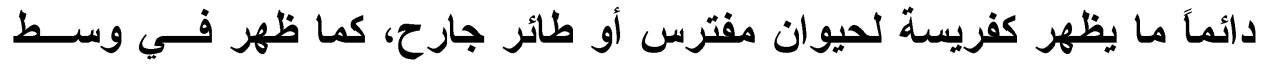

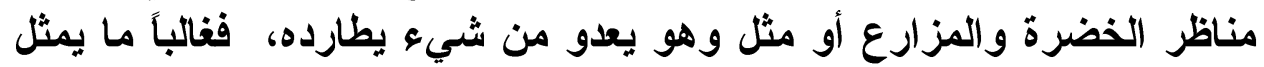
وهو في حالة ضعف.

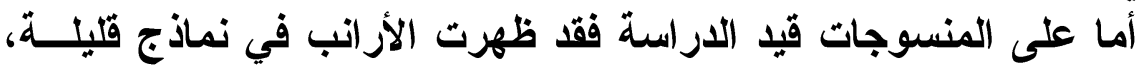
وقد مثلت أيضاً في وضع يشير إلى الخضوع واتلى الاستسلام ومنها:-

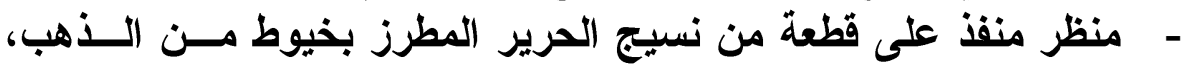

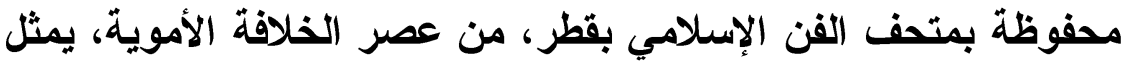

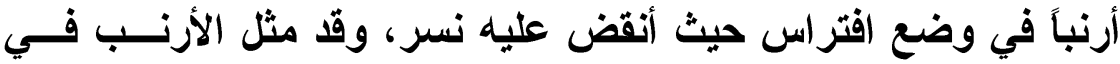

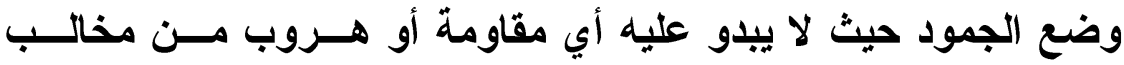

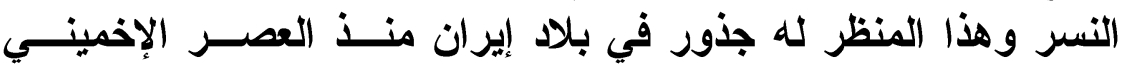

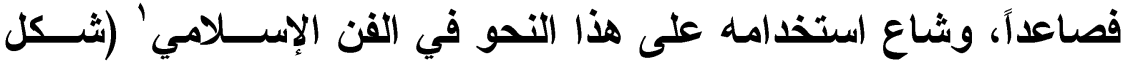

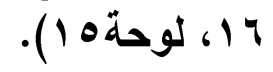
وقد مثل الأرنب في وضع الجمود فلا يبدو عليها أي حركة أو مقاومة

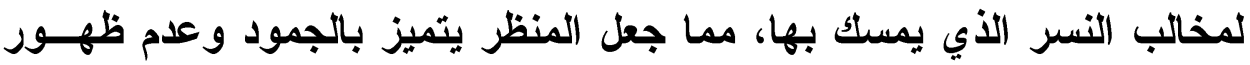
الحيوية و الحركة.

ولم يقتصر ظهور أثكال الأرانب على المنسوجات فحسب، فقد ظهرت أيضاً على التحف العاجية ومنها:- علبة من العاج محفوظة بمتحف فيكتوريا وألبرت بلندن، وهي مزينة مئة

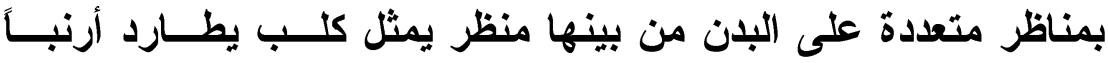

$$
\text { يعدو (لوحة V أو ). }
$$

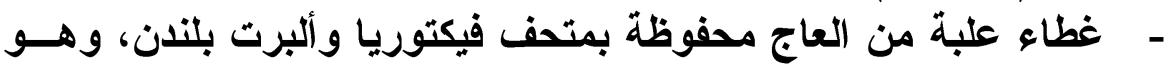

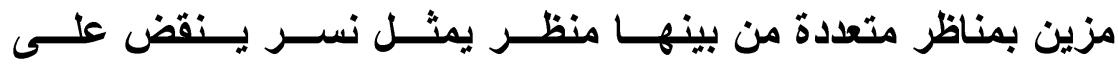

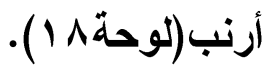

وقد تميزت مناظر الأرانب المنفذة على التحف السابقة بالتثابه الثديا مع مثيلاتها المنفذة على المنسوجات وذلتك من حيث وضع الجمات الجمود الأبي يتميز به الأرنب فالمنظر يخلو تماما من التعبير عن الحيوية و الحركة. 
- تميزت الرسوم الحيوانية المنفذة على المنسوجات الألدلسية بالثراء و التنوع فمنها رسوم الأسد و الفيل والغزلان والكلاب و الوعول والمئل والأراتب.

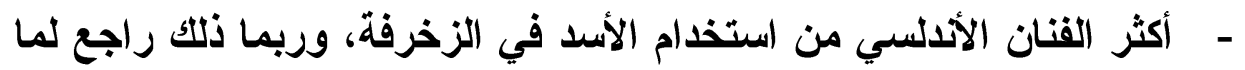
يمثله الأسد من رموز القوة والملكية ونحوها.

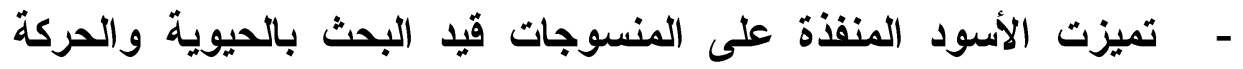

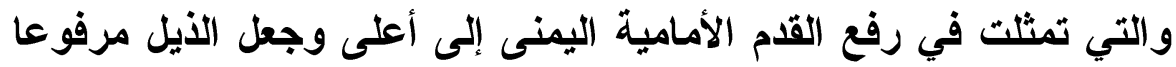
إلى أعلى في وضع يشير إلى الحركة السريعة والعدو خلف الفريسة. - - تثابهت أثكال الأسود المنفذة على المنسوجات إلى حد كبير مع مثيلاتها المنفذة على تحف العاج الأدلاية، والتي تبدو وكأنها منقولة عنها.

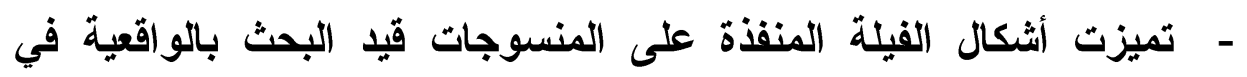
تنفيذها، كما تميزت بالتعبير عن الحيوية والحركة.

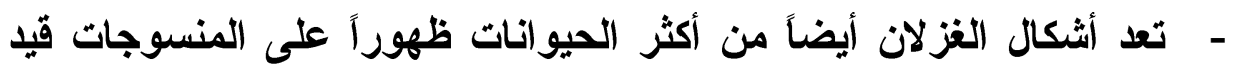
البحث، فقد ظهرث في مواقع متعددة وكاتت في الغالب تُمثل في وضع التع يشير إلى الخضوع والاستسلام. - تميزت رسوم الكلاب المنفذة على المنسوجات قيد البحث بالحيونة والحركة، فقد عبر الفنان عن الحيوية والحركة في كل رسوم الكلاب بحيث جعلها تعدو خلف بضها أو خلف الفريسة. - ظهرث أثكال الوعول على المنسوجات الألدلسية في الفترة المبكرة بينما فئل لم نجدها على منسوجات الفترة المتأخرة. - - تميزت أثكال الأرانب المنفذة على المنسوجات قيد البحث بالجمود التام

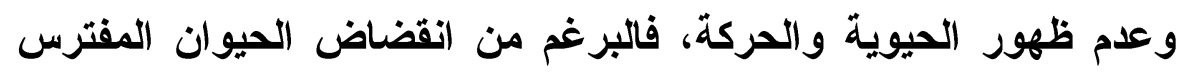
علية فلا تبدو علية أية مقاومة وذلك ريما تأثراً بالفن الاخميني.

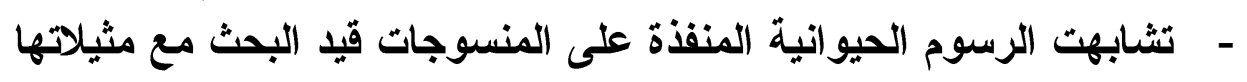
المنفذة على القنون التطبيقية الأدلسية خاصة المنفذة على التحف العاجية 
مجلة كلية الآداب، جامعة سوهاج، العدد الخامس والأربعون، الجزء الأول، أكتوبر IV I P
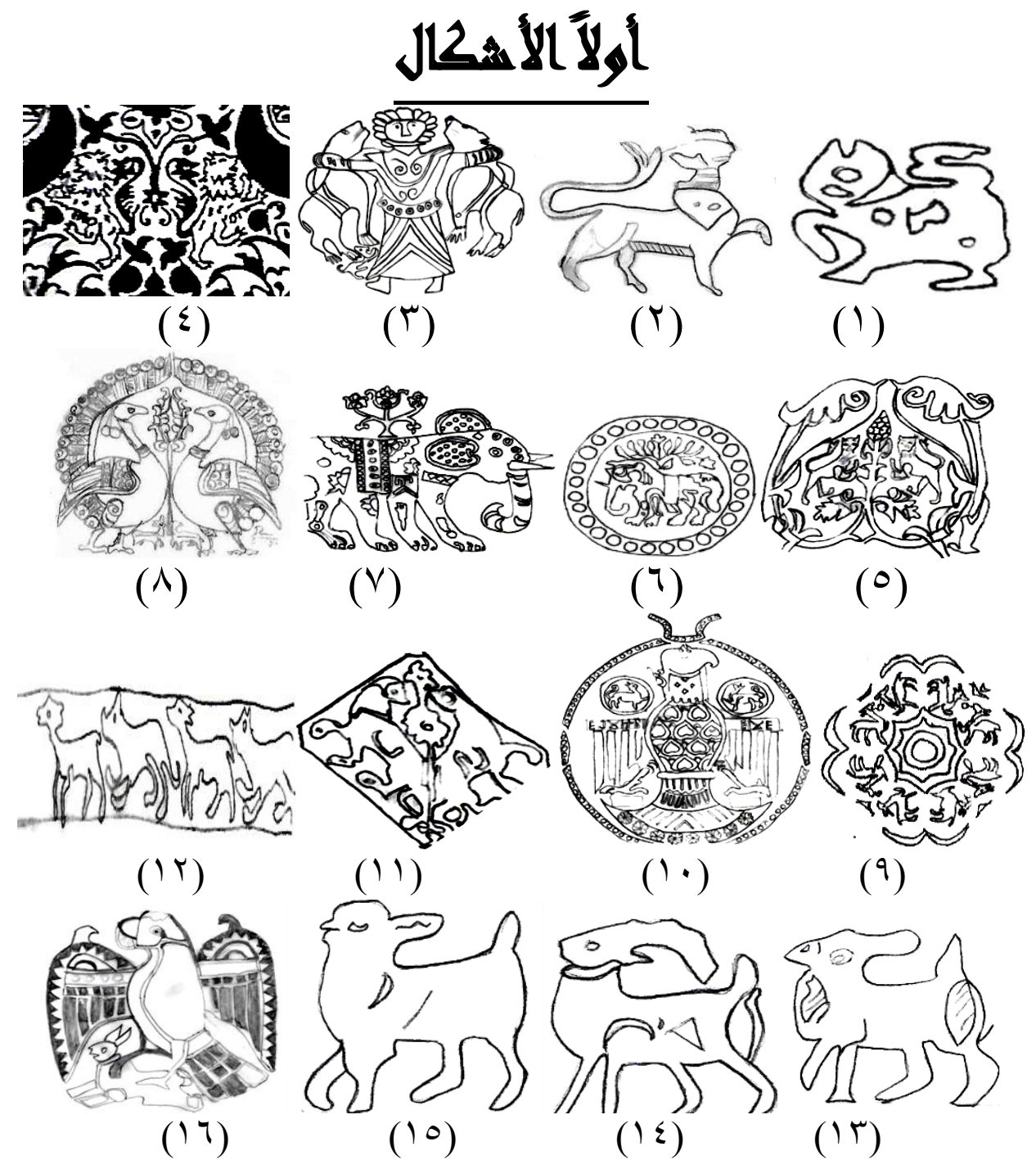
الرسوم الحيوانية المنفذة على المنسوجات الأندلسية الإسلامية

\section{ثمانيما اللوحايت}

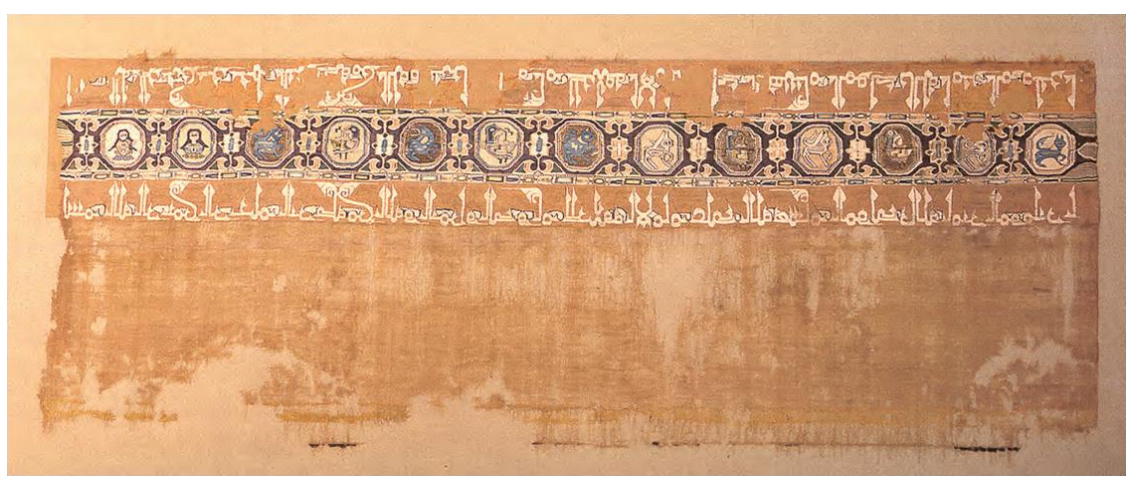

لوحة(1) قطعة من نسيج الحرير المطرز بخيوط من الذهب، المرية، محفوظة بالأكاديمية

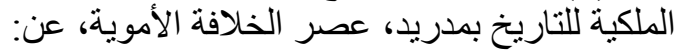

Cristina Partearroyo Lacaba, Estudio histórico-artístico de los tejidos de al-Andalus, Revista del Instituto del Patrimonio Histórico Español, Número 5 - 2005, pp 49.

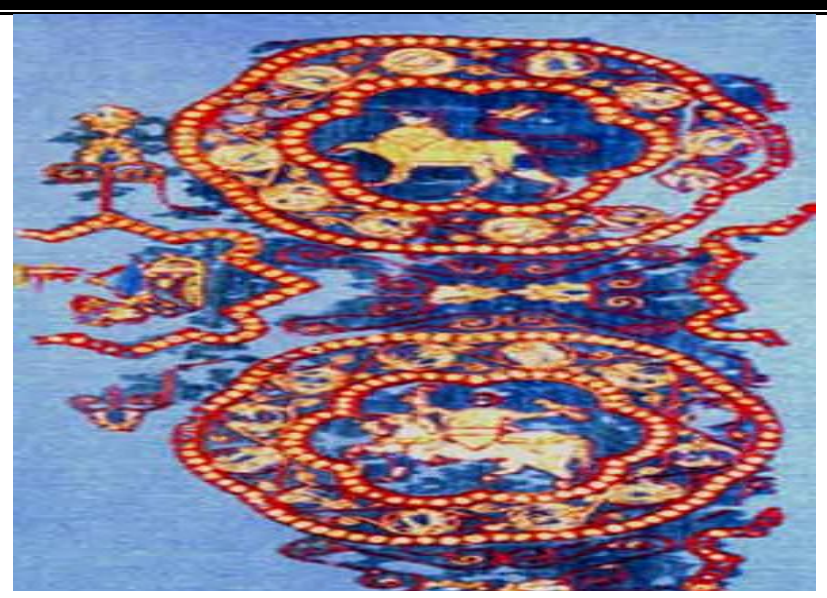

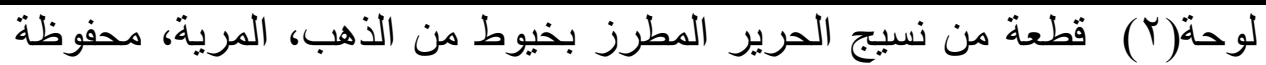
بالمتحف الوطني للعصور الوسطى(متحف كلوني)، عصر الخلافة الأموية، عن: http://www.musee-moyenage.fr/collection/oeuvre/fragment-suaire-saintlazare.html the last visit 24-8-2016. 


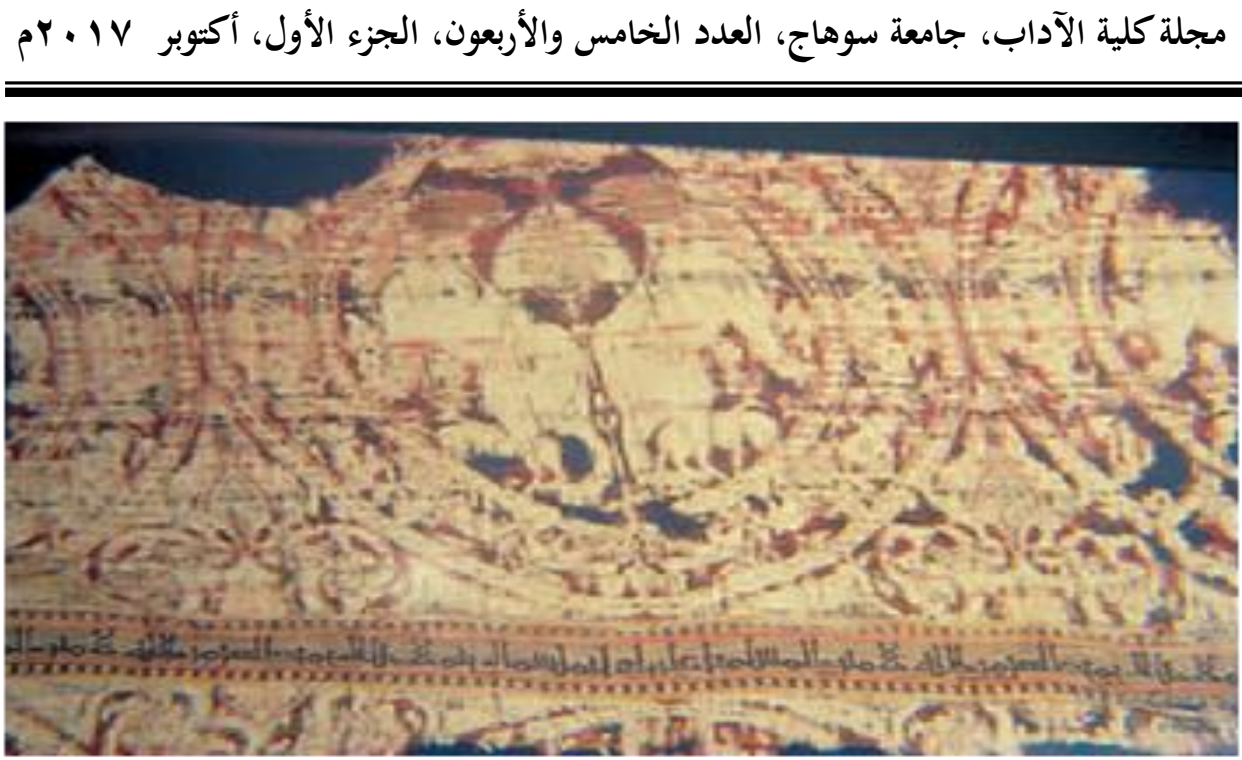

لوحة(r) قطعة من نسيج الحرير المطرز بخيوط من الذهب، محفوظة بكاتدرائية كوينتانا اورتينا، عصر المرابطين، عن:

Ettinghausen and Oleg Grabar, the art and architecture of Islam 650-1250, Yale university press, pelican history of art, n. d, P159.

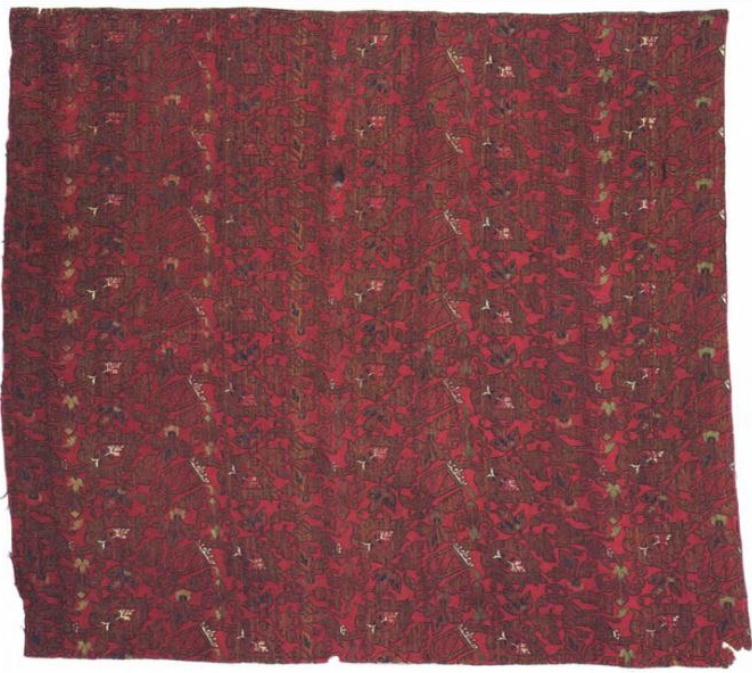

لوحة)(؛ ) قطعة من نسيج الحرير المطرز بخيوط من الذهب والفضة، محفوظة في متحف

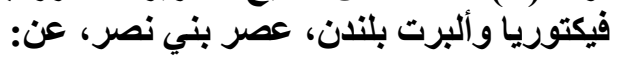
http://collections.vam.ac.uk/item/O15358/woven-silk-unknown/ the last visit 27-2-2016. 
الرسوم الحيوانية المنفذة على المنسوجات الأندلسية الإسلامية

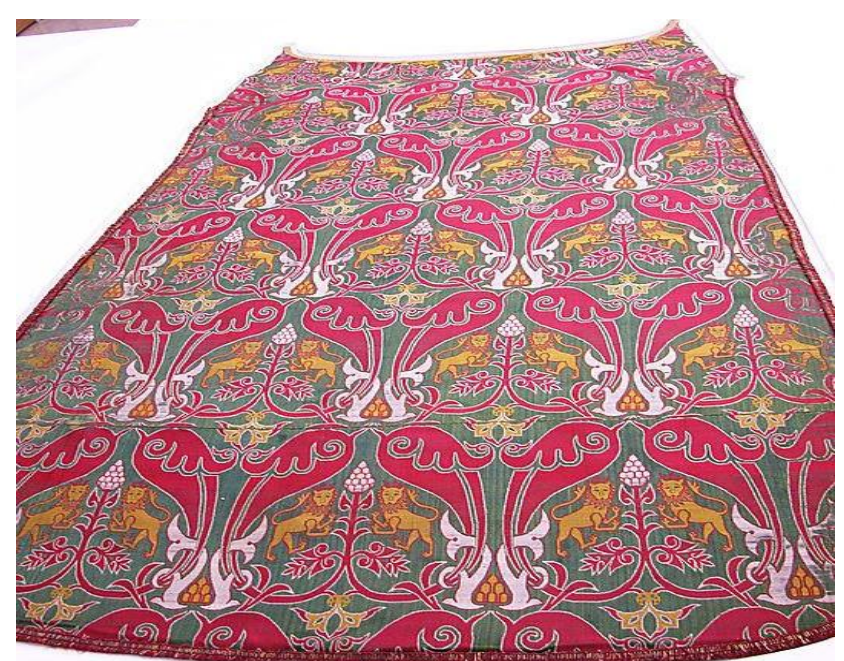

لوحة(0) قطعة من نسيج الحريز المطرز بخيوط من الذهب والفضة، محفوظة في متحف

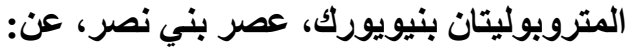

http://www.metmuseum.org/collection/the-collection-

online/search/447119?rpp the last visit 14-2-2016.

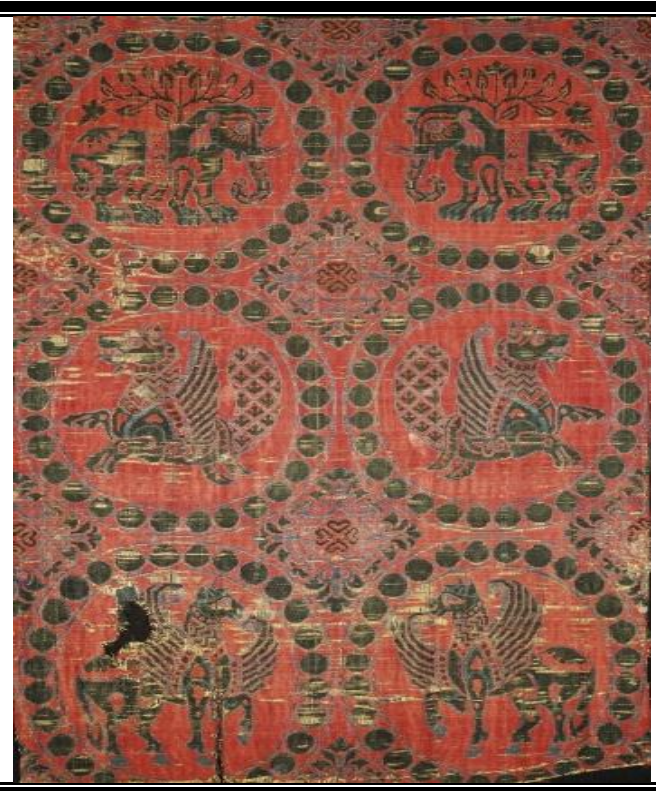

لوحة(7) قطعة من نسيج الحرير المطرز بخيوط من الذهب، محفوظ في متحف كوبر هيويت

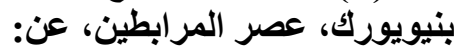

http://www.cooperhewitt.org/2015/01/19/elephants-and-winged-horses/

the last visit 2-1-2016. 
مجلة كلية الآداب، جامعة سوهاج، العدد الخامس والأربعون، الجزء الأول، أكتوبر IV P م

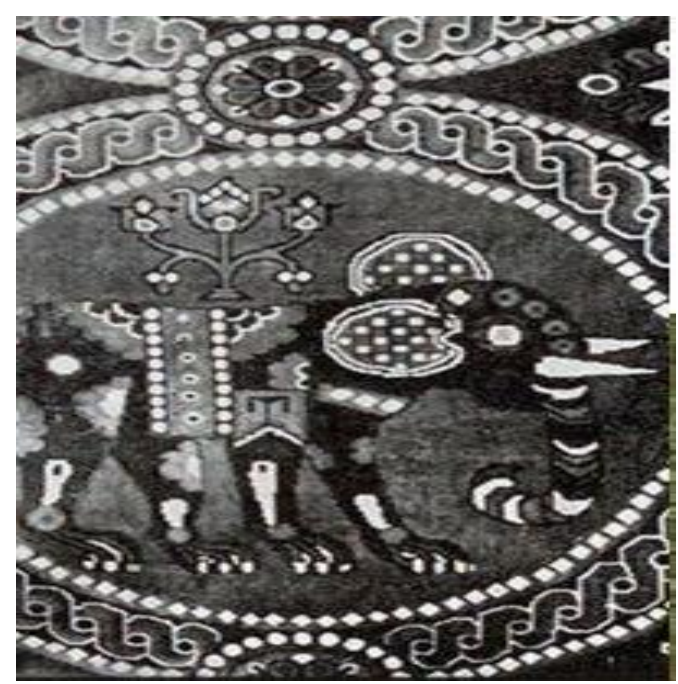

لوحة(V) قطعة من نسيج الحرير المطرز بخيوط من الأهب، محفوظة بمتحف كوبر هيويت

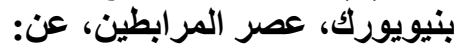
https://collection.cooperhewitt.org/objects/18130463/\#image-rights the last visit 5-3-2016.

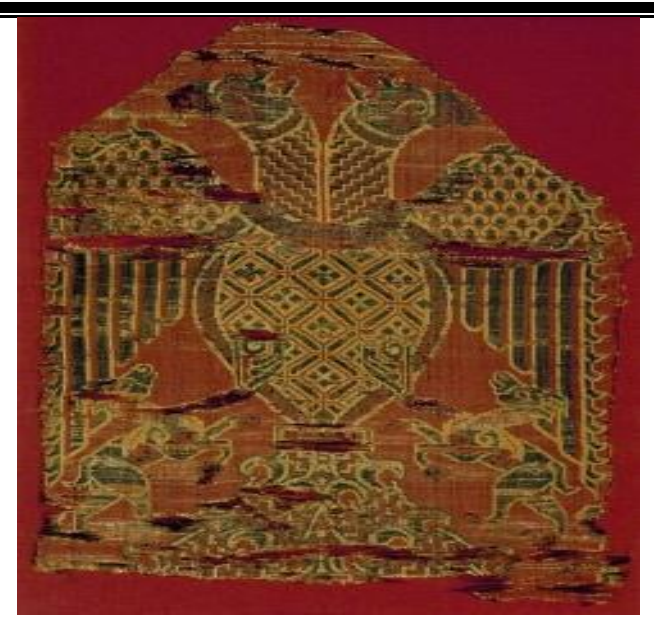

لوحة(^) قطعة من نسيج الحرير المطرز بخيوط من الأهب، محفوظة بمتحف الأقمشة والقنون الزخرفية بليون، عصر ملوك الطوائف، عن:

Cristina Partearroyo Lacaba, op.cit, P 884. 
الرسوم الحيوانية المنفذة على المنسوجات الأندلسية الإسلامية
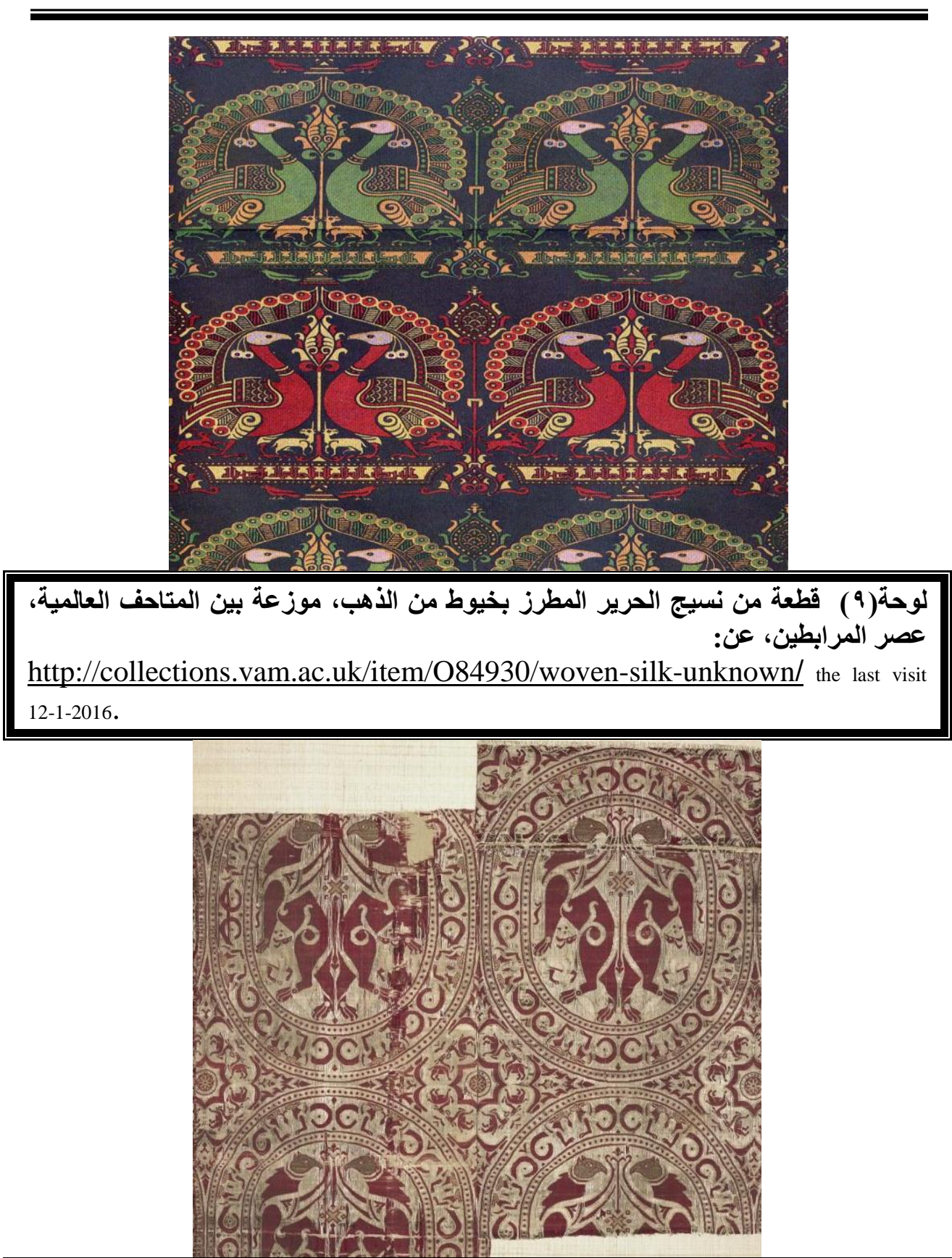

لوحة المرابطين، عنة من نسيج الحرير المطرز بخيوط من الذهب، موزعة بين المتاحف العالمية،

http://www.metmuseum.org/collections/search-the-collections/140008792?img the last visit 28-32016. 
مجلة كلية الآداب، جامعة سوهاج، العدد الخامس والأربعون، الجزء الأول، أكتوبر IVY IV

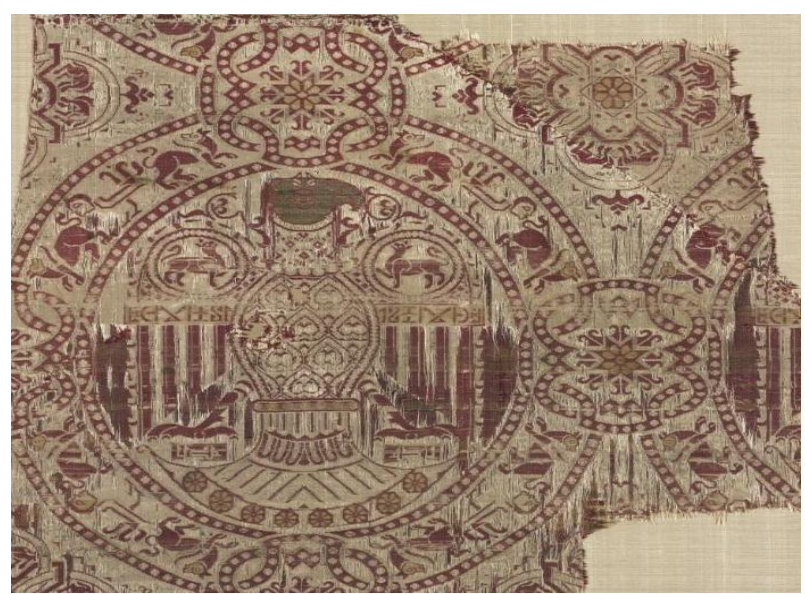

لوحة(11) قطعة من نسيج الحريز المطرز بخيوط من الأهب، محفوظة بمتحف الفن بكليفلاند،

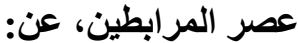

http://www.clevelandart.org/art/1952.15 the last visit 7-1-2016.

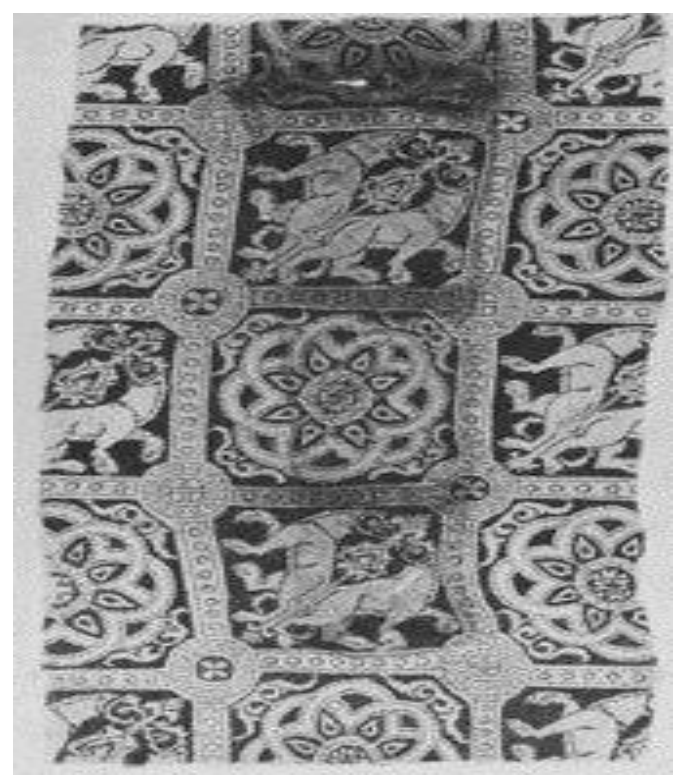

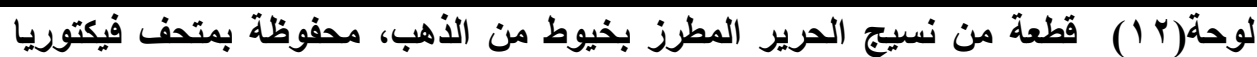
وألبرت بلندن، عصر المرابطين، عن: http://collections.vam.ac.uk/item/O86782/fragment-unknown/ the last visit 26-1-2016. 
الرسوم الحيوانية المنفذة على المنسوجات الأندلسية الإسلامية

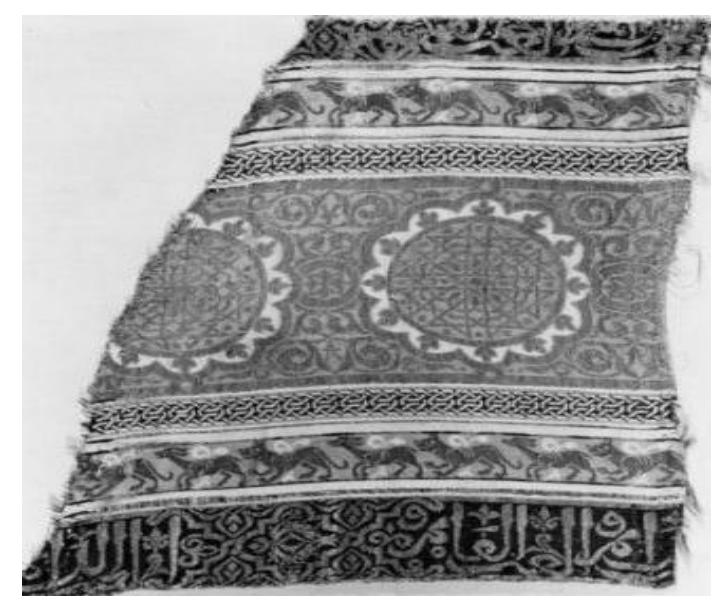

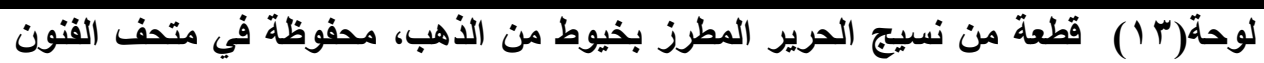

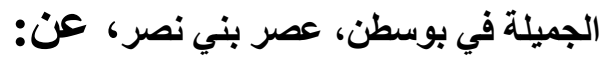
http://www.mfa.org/collections/object/textile-fragment-67016 the last visit 21-2-2016.

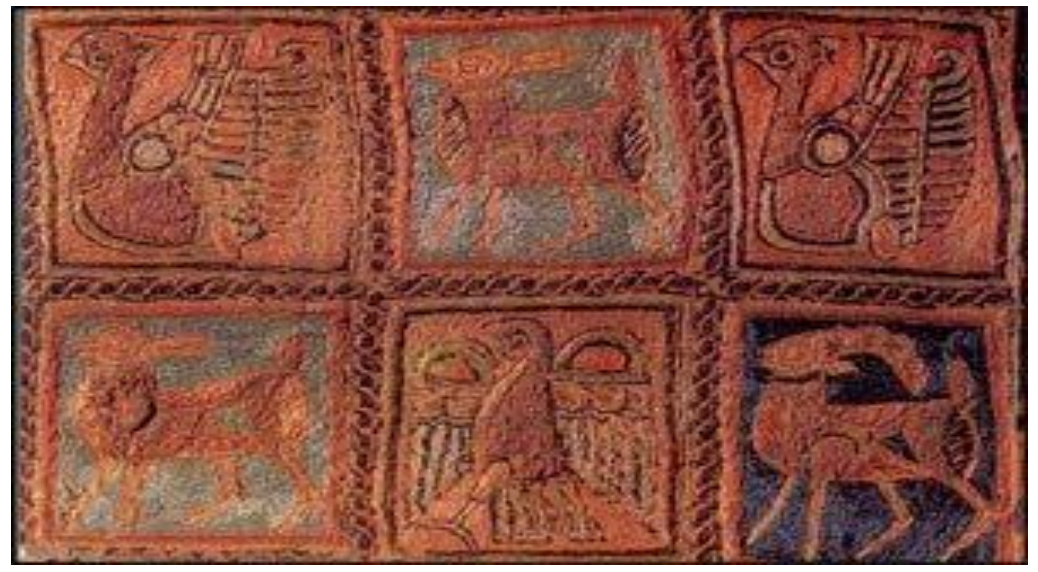

لوحة(ء 1) قطعة من نسيج الحرير المطرز بخيوط من الذهب، اشبيلية، تمثل بطانة لغطاء

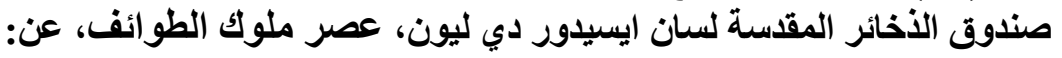
http://medieval.webcon.net.au/extant_almoravid.html the last visit 80-5-2014. 
مجلة كلية الآداب، جامعة سوهاج، العدد الخامس والأربعون، الجزء الأول، أكتوبر IV P P

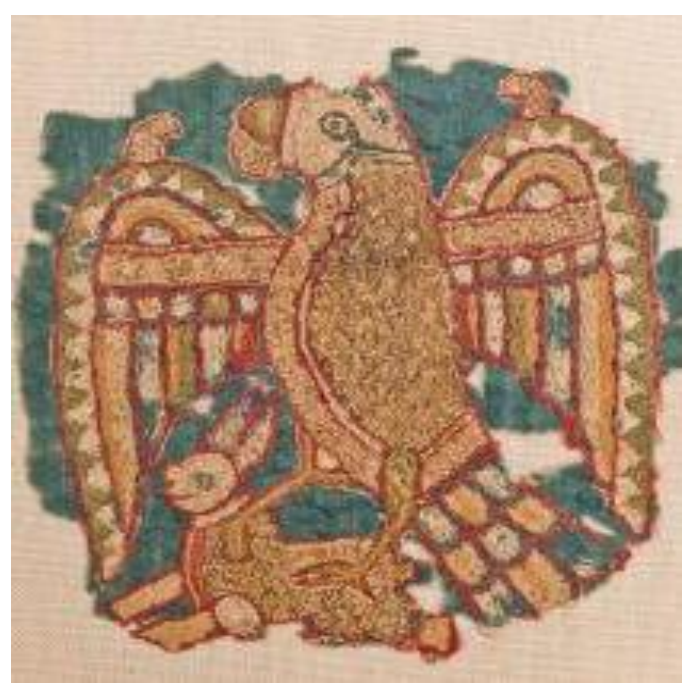

لوحة(1 1) قطعة من نسيج الحرير المطرز بخيوط من الأهب، المرية، محفوظة بمتحف الفن

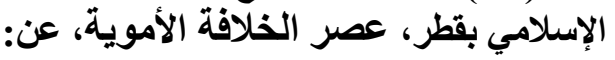

http://www.google.com/culturalinstitute/asset-viewer/silk-

embroidered-fragmen t/UAGG7CDHMCYTeQ?projectId the last visit 80-5-2014.

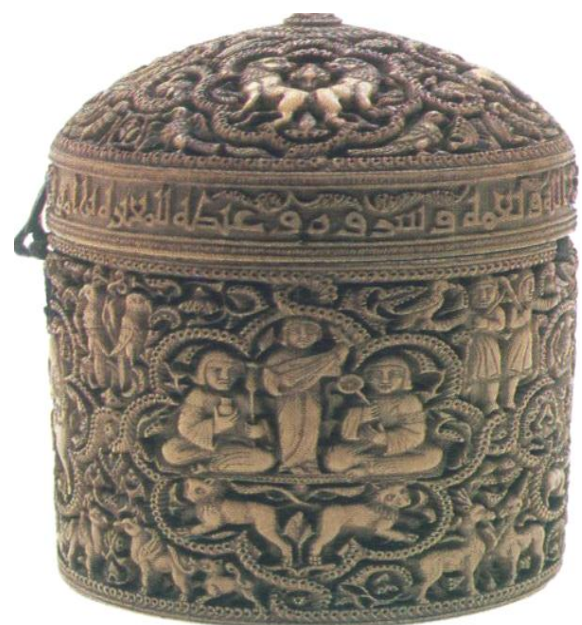

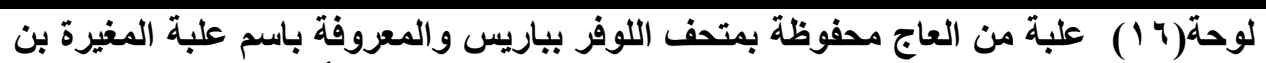

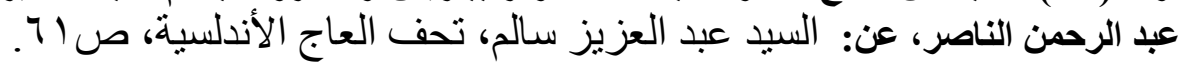


الرسوم الحيوانية المنفذة على المنسوجات الأندلسية الإسلامية

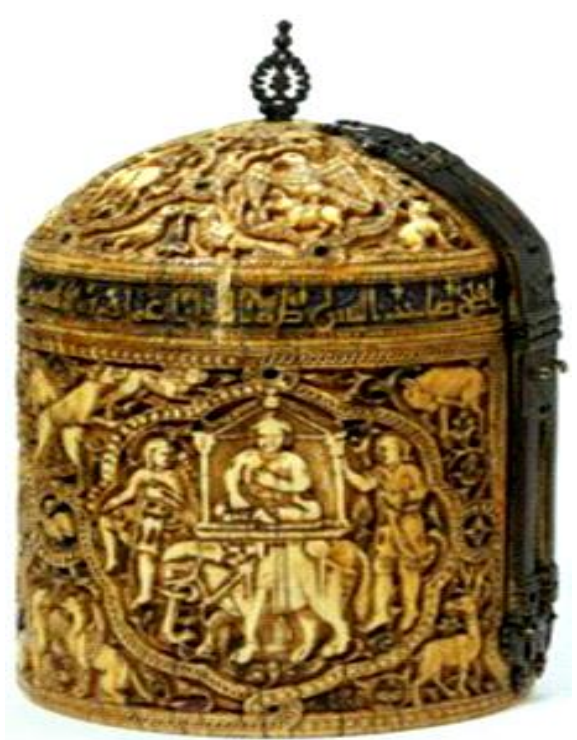

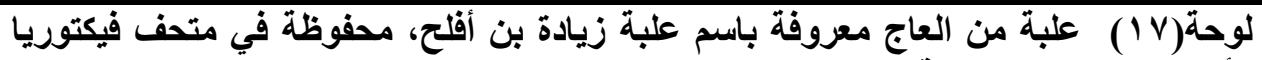

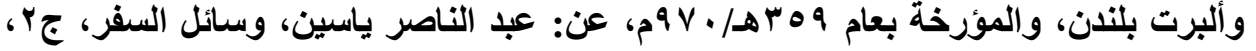

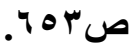

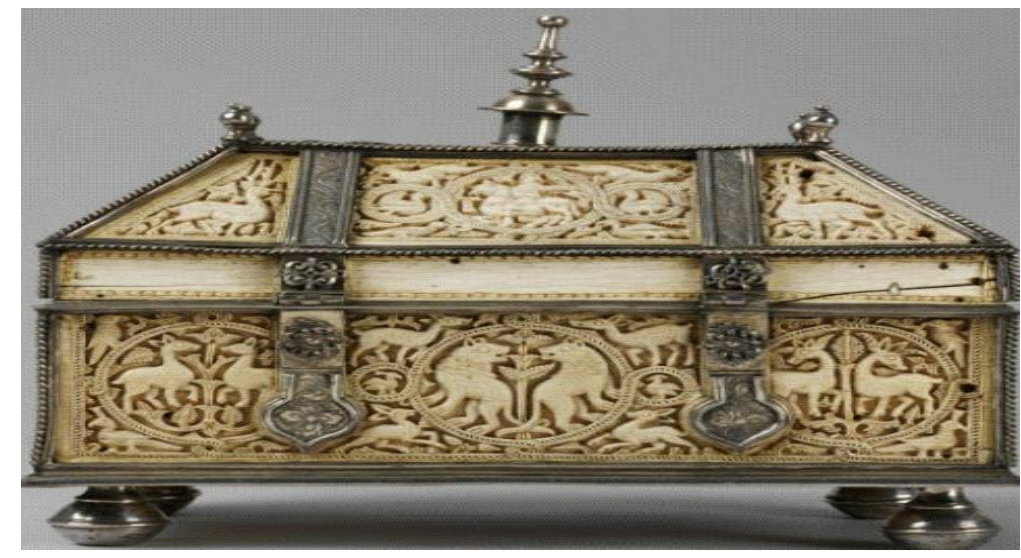

لوحة(1/1) صندوق من العاج، محفوظ بمتحف فيكتوريا وألبرت بلندن، عن: السيد عبد العزيز

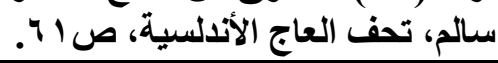


مجلة كلية الآداب، جامعة سوهاج، العدد الخامس والأربعون، الجزء الأول، أكتوبر IV P م

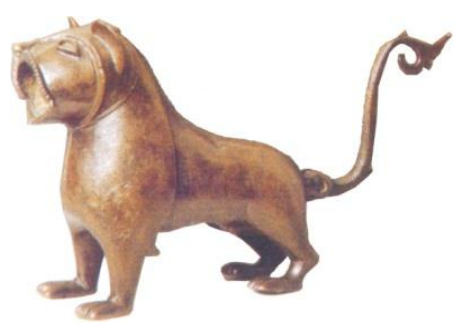

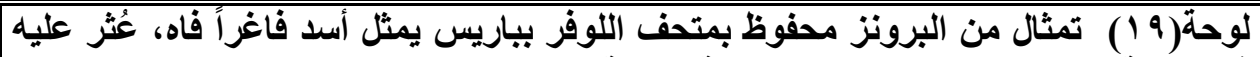

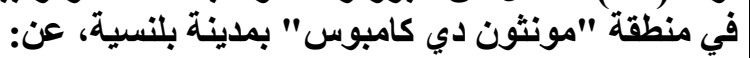

Jerrilynn D.Dodds, op.cit., P 271.

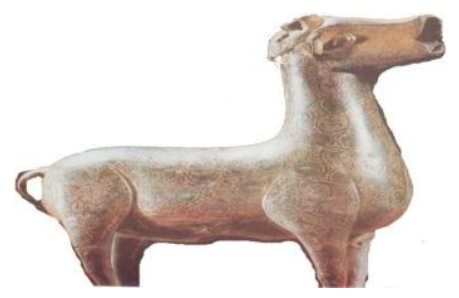

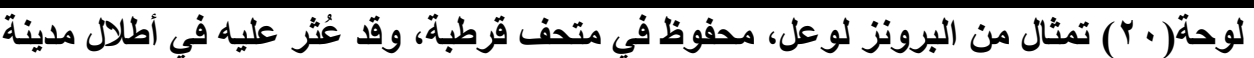

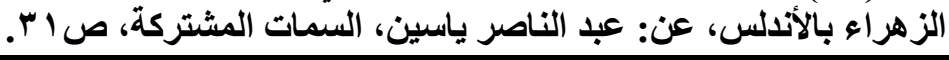

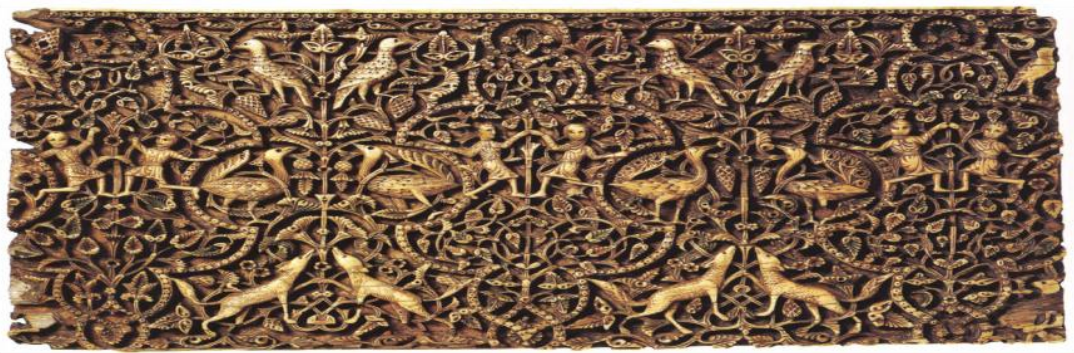

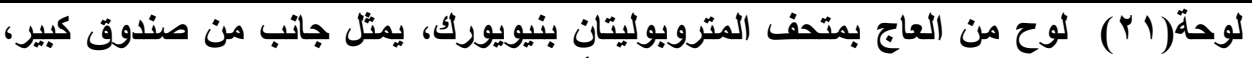

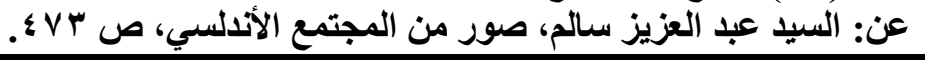

